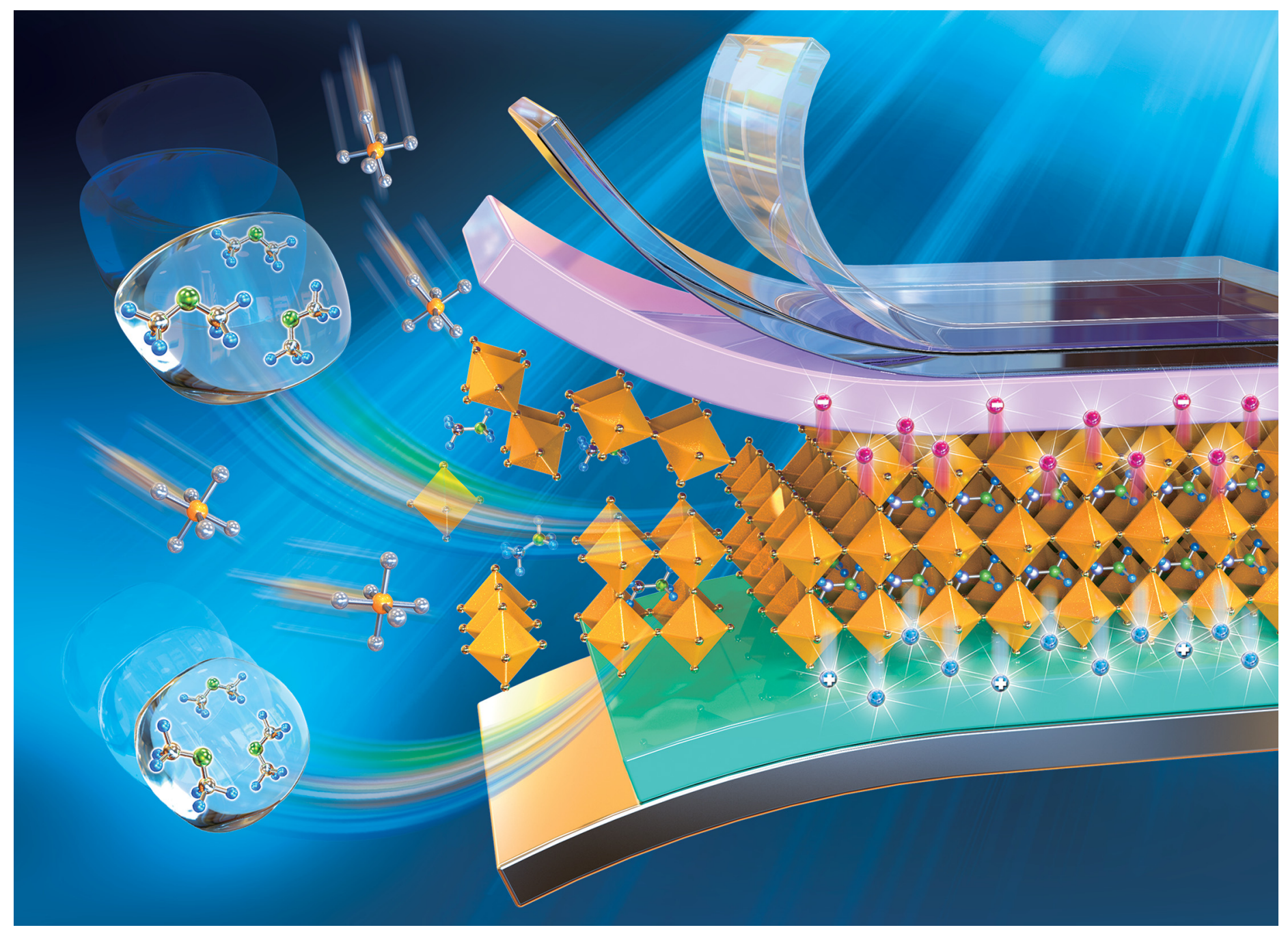

Showcasing research from Professors Antonio Abate and Meng Li's laboratory, Department of active materials and interfaces for stable perovskite solar cells (EE-NMIP), Helmholtz Center Berlin for Energy and Materials, Berlin, Germany.

Challenges in tin perovskite solar cells

Tin perovskites could be the next rising star of the photovoltaics world and represent an environmentally friendly alternative to lead perovskites. However, they show $10 \%$ less efficiency than lead perovskites in practice. This unexpected low efficiency is attributed to unstable solvents and materials, bad energy bands alignment, Sn(II) oxidation, and fast crystallization dynamics. Addressing these four challenges would unlock the inherent potential of tin perovskites. This would be a significant step towards new efficient, safe and affordable photovoltaic technology.

\section{As featured in:}

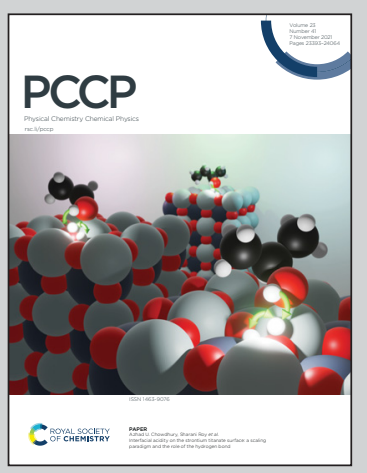

See Antonio Abate, Meng Li et al., Phys. Chem. Chem. Phys., 2021, 23, 23413. 
Check for updates

Cite this: Phys. Chem. Chem. Phys., 2021, 23, 23413

Received 9th June 2021

Accepted 20th August 2021

DOI: $10.1039 / d 1 c p 02596 a$

rsc.li/pccp

\title{
Challenges in tin perovskite solar cells
}

\author{
Mahmoud Aldamasy, ${ }^{a b}$ Zafar Iqbal, ${ }^{a}$ Guixiang Li, (D) ${ }^{a}$ Jorge Pascual, ${ }^{a}$ \\ Fahad Alharthi, (D) ${ }^{c}$ Antonio Abate ${ }^{\star a c}$ and Meng Li (D) *ad
}

\begin{abstract}
Perovskite solar cells are the rising star of third-generation photovoltaic technology. With a power conversion efficiency of $25.5 \%$, the record efficiency is close to the theoretical maximum efficiency of a single-junction solar cell. However, lead toxicity threatens commercialization efforts and market accessibility. In this context, Sn-based perovskites are a safe alternative. Nevertheless, the efficiency of $\mathrm{Sn}$-based devices falls far behind the efficiency of Pb-based counterparts. This concise review sheds light on the challenges that the field faces toward making Sn-based perovskites the perovskite photovoltaic benchmark. We identified four key challenges: materials and solvents, film formation, Sn(॥) oxidation, and energy band alignment. We illustrate every single challenge and highlight the most successful attempts to overcome them. Finally, we provide our opinion on the most promising trends of this field in the future.
\end{abstract}

\section{Motivation}

Exploring the photoactive properties of halide perovskites started twenty years ago as a scientific curiosity, and it resulted

\footnotetext{
${ }^{a}$ Department of Novel Materials and Interfaces for Photovoltaic Solar Cells, Helmholtz-Zentrum Berlin für Materialien und Energie GmbH, Hahn-Meitner-Platz 1, 14109 Berlin, Germany. E-mail: meng.li@helmholtz-berlin.de, antonio.abate@helmholtz-berlin.de

${ }^{b}$ Egyptian Petroleum Research Institute, Nasr City, P.O. 11727, Cairo, Egypt ${ }^{c}$ Chemistry Department, Science College, King Saud University, P.O. Box 2455, Riyadh 11451, Saudi Arabia

${ }^{d}$ Key Lab for Special Functional Materials of Ministry of Education, National \& Local Joint Engineering Research Center for High-efficiency Display and Lighting Technology, School of Materials Science and Engineering, and Collaborative Innovation Center of Nano Functional Materials and Applications, Henan University, Kaifeng 475004, China
}

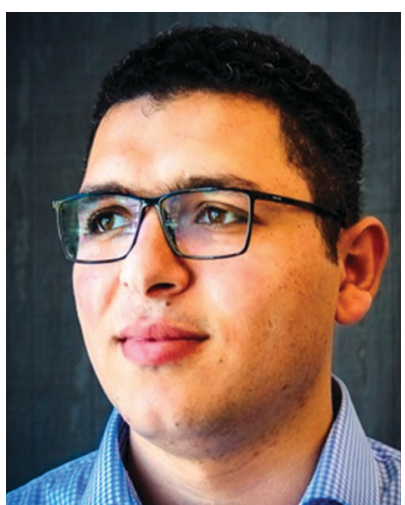

Mahmoud Aldamasy
Mahmoud Aldamasy received his MPhil degree in Physical Chemistry from Zagazig University, Egypt. He has been working at Egyptian petroleum research institute (EPRI) on petroleum applications. He is now a DAAD PhD scholar at Helmholtz Center Berlin for Energy and Materials and working on finding new solvents for tin perovskites at the department of novel materials and interfaces for photovoltaic solar cells.

in a novel type of photovoltaics and optoelectronics. ${ }^{1}$ Perovskite solar cells (PSCs) grabbed the attention from the photovoltaic community due to their ease of fabrication, optimum optoelectronic properties, low cost, material abundance, and increasing power conversion efficiencies (PCEs) that quickly increased from $3.8 \%$ in 2009 to $25.5 \%$ in $2021 .^{2}$ These advantageous characteristics encouraged an unprecedented number of researchers to work on developing PSCs. With the inherited knowledge and techniques from previously developed technologies, especially silicon and organic photovoltaics, notable progress has been made in the last ten years to overcome the hurdles that exist in industrialization and commercialization of PSCs. ${ }^{3}$ It is the first time an emerging technology has quickly overtaken older technologies like dye-sensitized solar cells (DSSC) and compete with other commercially available

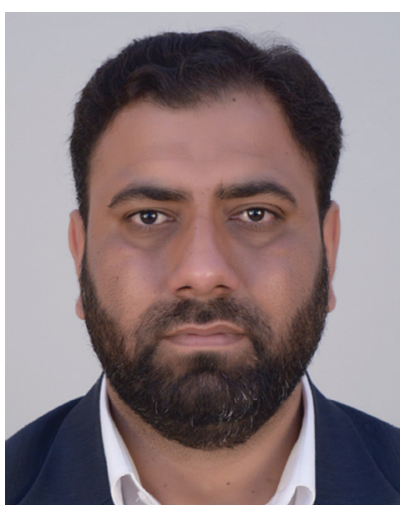

Zafar Iqbal
Zafar Iqbal is a DAAD PhD Scholar at Helmholtz-Zentrum Berlin für Materialien und Energie (HZB). He has earned his MPhil degree in Physical Chemistry from Quaid-i-Azam University, Islamabad. He has been working as a researcher at Department of Chemistry and Chemical Engineering, LUMS, Lahore. He is working on Inorganic tin perovskite halides for energy applications. 
technologies such as crystalline silicon solar cells, cadmium telluride (CdTe), and copper indium gallium selenide (CIGS) in terms of power conversion efficiency (PCE). ${ }^{4-6}$ However, longterm stability ${ }^{7,8}$ and lead toxicity ${ }^{9,10}$ still hinder PSCs from accessing the market, at least on the short term. ${ }^{11}$

The toxicological nature of lead increases fears of environmental implications that could hinder PSCs' investments and market adoption. This perspective made the replacement or reduction of lead in PSCs a core activity of several research groups. Nevertheless, the current record efficiencies rely on lead as the metallic component inside the perovskite crystal. ${ }^{12}$

According to the US Environmental Protection Agency (EPA), the maximum allowed lead concentrations are $0.15 \mu \mathrm{g} \mathrm{m} \mathrm{m}^{-3}$ and $0.15 \mu \mathrm{g} \mathrm{L}^{-1}$ in air and water, respectively. The directives adopted by the European Union against the use of lead limit its concentration in electronic devices to less than $0.1 \%$ of the weight of each homogeneous material inside the device. However, current state-of-the-art lead-based

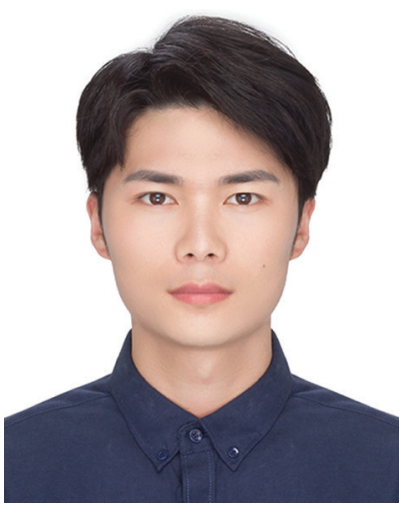

Guixiang Li
Guixiang Li is currently working as a PhD student at HelmholtzZentrum Berlin für Materialien und Energie GmbH. Previously, he received his master degree from South China University of Technology in 2019. Guixiang's current research includes solution-engineered lead-free tinbased perovskite materials and their optoelectronic applications. perovskite materials exceed this threshold by at least tenfold taking into consideration the high water solubility of lead compounds used in PSCs. ${ }^{13}$ As a backup strategy, the photovoltaic community started looking for a lead-free perovskite technology ${ }^{14-16}$ in order to lower or even eliminate lead from PSCs completely. ${ }^{115}$

Applying the perovskite dimensionality rules, we realize that a very limited number of metal ions could form a highperforming and environmentally friendly perovskite structure, ${ }^{17,18}$ such as Bi/Sb-based halides, a semi-perovskite structure, double perovskites, and Sn/Ge-based perovskites. ${ }^{18}$ Sn attracted the most attention among these candidates as it fulfills the charge balance, coordination, and ionic size prerequisites. $^{19}$ Tin perovskites carry many environmental advantages over lead perovskites. Tin could be more toxic to living organisms than lead when leaked to the environment. However, it is less bioavailable due to the lower water solubility of oxygenated $\mathrm{Sn}^{4+}$ compounds. ${ }^{20,21}$
Jorge Pascual

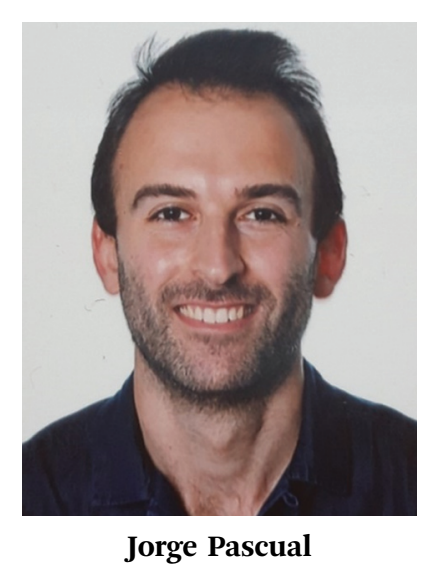

Jorge Pascual Mielgo is a post-doc in Helmholtz-Zentrum Berlin under the supervision of Antonio Abate. His current research focuses on the development of efficient and stable lead-free tin halide perovskite devices. He graduated in Chemistry from the University of the Basque Country and specialised in the field of Organic Chemistry. In 2019, he obtained his PhD degree in Polymat (Donostia-San Sebastian) on the study of fullerenes as additives in metal halide perovskite thin films.

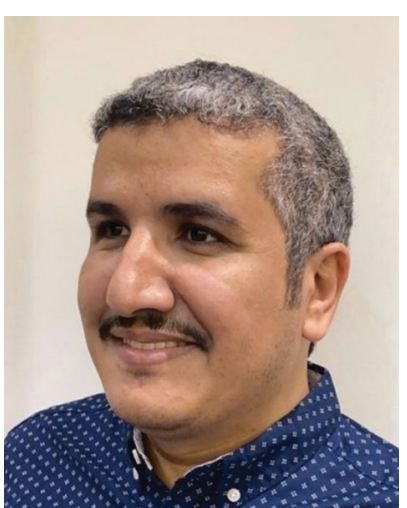

Fahad Alharthi
Fahad A. Alharthi is an associate professor at King Saud University in Saudi Arabia. He got his PhD from Hull university, UK in 2016. His research interests are focussed on inorganic nanomaterials for renewable energy and environmental remediation.

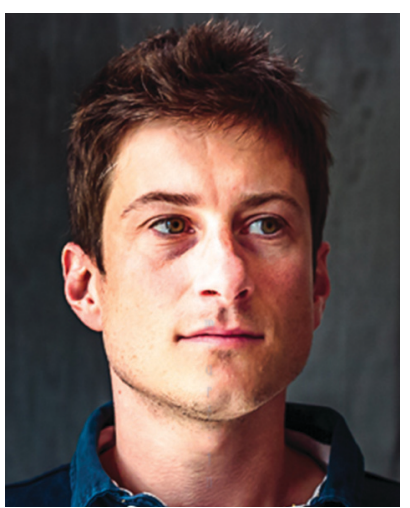

Antonio Abate
Antonio Abate is team leader at Helmholtz-Centrum Berlin and a tenure track professor at University of Naples Federico II. He is researching solar energy conversion with perovskite solar cells. Before the current position, Antonio was leading the solar cell research at the University of Fribourg in Switzerland. He was a Marie SkłodowskaCurie Fellow at École Polytechnique Fédérale de Lausanne. He worked for four years as a postdoctoral researcher at the University of Oxford and the University of Cambridge. Antonio graduated from University of Naples Federico II in 2006, and he got his PhD at Politecnico di Milano in 2011. 
Tin perovskites show exciting electrical and optoelectronic properties enabling them to excel lead perovskites in terms of photovoltaic performance. The outer electronic configuration of tin is very similar to that of lead $\left(\mathrm{ns}^{2}, \mathrm{np}^{2}\right)$, and the atomic size of both elements is comparable $(1.49 \AA$ for $\mathrm{Pb}(\mathrm{II})$ and $1.35 \AA$ for $\mathrm{Sn}(\mathrm{II}))$. However, the atomic number of lead is higher than that of tin, thanks to the relativistic effect. ${ }^{22}$ Compared to lead perovskites, tin perovskites show a very sharp absorption edge with a direct bandgap ranging from 1.35 to $1.4 \mathrm{eV}$, close to the Shockley-Queisser limit with an estimated theoretical efficiency of above $30 \%$ (e.g., $33.7 \%$ at $1.34 \mathrm{eV}$ ). Tin perovskites also show higher charge mobilities and a higher external photoluminescence quantum yield (PLQY). ${ }^{23,24}$ These properties would enable Sn-based perovskites to overcome their $\mathrm{Pb}$ analogs in terms of efficiency while already showing very promising applications for quantum dots, sensors, detectors, and transistors. ${ }^{25,26}$

Currently, tin perovskites still lie in the back behind $\mathrm{Pb}$-based counterparts in terms of efficiency due to several causes. First, Sn(II) oxidation to Sn(Iv), which causes self-pdoping and devastates the performance of the devices. Second, fast crystallization dynamics, Sn-based perovskites crystallize very fast compared to $\mathrm{Pb}$-based perovskites, which results in nonuniform crystallization, smaller perovskite domains, pinholes, and a considerable amount of defects. Third, energy band alignment, most of the charge transport layers are designed primarily for Pb-based perovskites, but when used blindly for Sn-based perovskites, we find energy band mismatch, which is very harmful to the overall performance of Sn-perovskite devices (Fig. 1). ${ }^{22}$

\section{Chronological overview}

The first successful attempt to synthesise Sn-based perovskites dates back to 1974 by Scaife and co-workers, where they synthesized and characterized all-inorganic $\mathrm{CsSnX}_{3}$, where $\mathrm{X}_{3}$ is $\mathrm{Cl}_{3}, \mathrm{BrCl}_{2}, \mathrm{Br}_{3}, \mathrm{Br}_{2} \mathrm{I}, \mathrm{BrI}_{2}$, and $\mathrm{I}_{3} \cdot{ }^{27}$ Five years later, Parry and co-workers prepared and studied the optoelectronic properties

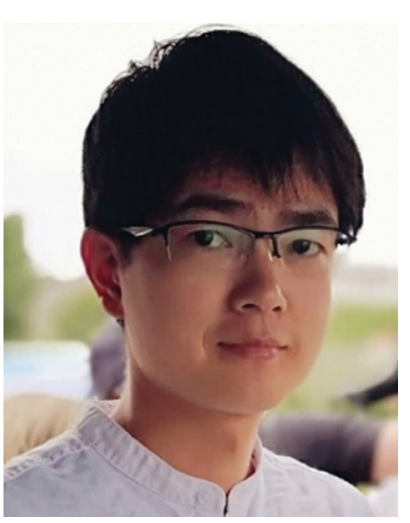

Meng Li
Meng Li received his $P h D$ degree in materials science and engineering under the supervision of Prof. Liang-Sheng Liao and Prof. Zhao-Kui Wang from Soochow University, P. R. China, in 2018. Currently, he is a postdoctoral research fellow in the laboratory of Prof. Antonio Abate at the Helmholtz-Zentrum Berlin für Materialien und Energie (HZB), Germany. His primary research interest is focused on organic and inorganic/organic hybrid materials for application in solar cells. His main research topic is non-toxic photovoltaic materials and devices for outdoor and indoor applications.

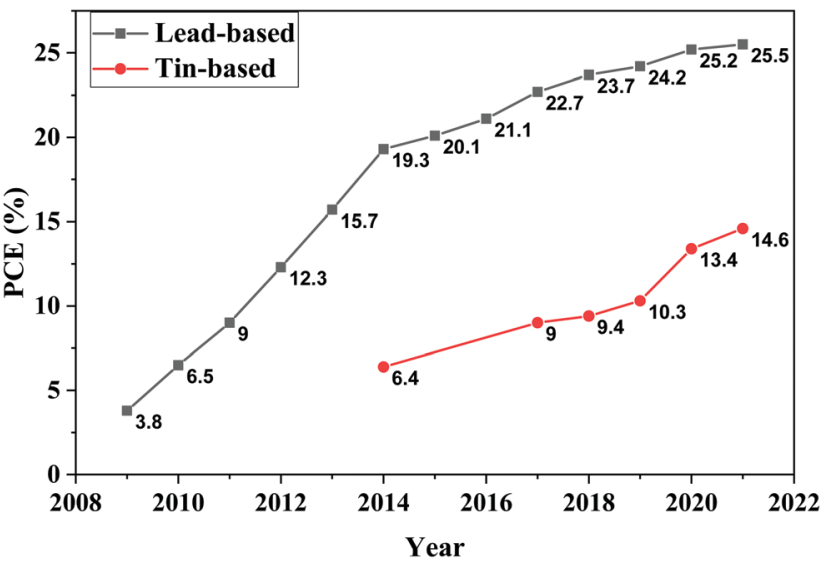

Fig. 1 Efficiency progress of Sn- and Pb-based PSCs over time.

of the same all-inorganic Sn-based perovskite materials. ${ }^{28,29}$ However, hybrid Sn perovskites were never reported until 1988 when Yamada and co-workers prepared and investigated the phase transition properties of $\mathrm{MASnBr}_{3}\left(\mathrm{MA}=\mathrm{CH}_{3} \mathrm{NH}_{3}{ }^{+}\right) \cdot{ }^{30-32}$ From the mid-90s till 2001, Mitzi and co-workers studied the dimensionality and structural engineering of different structures of layered perovskites. ${ }^{33}$ In addition, they reported more detailed studies on the thermal, optical, magnetic, and electrical properties of layered Sn-based perovskites. ${ }^{19,34}$ It was also reported that the conductivity of such layered perovskites varies with the thickness or the number of perovskite layers; in other words, its electric behavior changes from semiconducting to metallic by increasing the number of perovskite layers. ${ }^{35,36}$ Furthermore, they exploited the optoelectronic properties, low cost, and low-temperature processability of Sn-based perovskites by demonstrating them as a semiconducting channel in thin-film field-effect transistors; this was the first reported electronic application of a hybrid lead-free tin-based halide perovskite material. ${ }^{37,38}$

Sn-Based perovskite materials started to attract attention from the photovoltaic community, especially after 2009 when Chung and co-workers reported the first solar cell based on $\mathrm{MAPbI}_{3}$ and $\mathrm{MAPbBr}_{3}$ perovskite photoactive materials. ${ }^{1}$ The first report about Sn perovskites was published in 2012 by Chung and co-workers, where they employed $\mathrm{CsSnI}_{3}$ doped with $\mathrm{SnF}_{2}$ as a hole transporting material (HTM) in a DSSC using dye N719 as the solar absorber, and they achieved a PCE of $10.2 \%(8.51 \%$ with a mask $) .{ }^{39}$ Later on, in the same year, Shum and co-workers employed $\mathrm{CsSnI}_{3}$ with a bandgap of $1.3 \mathrm{eV}$ as an independent light absorber in a Schottky solar cell and achieved a PCE of $0.9 \%{ }^{40}$ In 2013 , the PV community started to reinvestigate and exploit the optoelectronic properties of Sn-based perovskites as a potential candidate for solar light harvesting. ${ }^{41-44}$ The first promising efficiencies were reported in 2014 when Snaith and co-workers reported a PCE of $6.4 \%$ based on $\mathrm{MASnI}_{3}$ as a light absorber. ${ }^{15}$ Four days later, Hao and co-workers reported an efficiency of around 5.7\% utilizing $\mathrm{MASnI}_{3}$ and $\mathrm{MASnI}_{3-x} \mathrm{Br}_{x}$ as photoactive absorber materials. ${ }^{16}$ These initial results gave the solar cell community 
a sense of trust in Sn-based materials as potential nontoxic contenders for the rocketing Pb-based perovskites. ${ }^{45-47}$

In early 2016, Lee and co-workers reported $\mathrm{FASnI}_{3}$-based PSCs $\left(\mathrm{FA}=\mathrm{NH}_{2} \mathrm{CH}=\mathrm{NH}_{2}^{+}\right)$utilizing $\mathrm{SnF}_{2}$-pyrazine complexes to guarantee a uniform dispersion of $\mathrm{SnF}_{2}$ to avoid perovskite phase separation; an efficiency of $4.8 \%$ was achieved, and the encapsulated cells maintained $98 \%$ of its initial efficiency for 100 days. ${ }^{48,49}$ Later on, Liao and co-workers achieved a PCE of $6.22 \%$ based on inverted planar $\mathrm{FASnI}_{3}$ utilizing the solvent engineering method. ${ }^{50}$ In 2017 , the PSC community witnessed remarkable achievements in terms of both efficiency and stability of Sn-based PSCs, most of which were based on inspired techniques from Pb-based PSCs such as cation mixing, ${ }^{51}$ incorporating low dimensional perovskites, ${ }^{52}$ and utilizing hollow ${ }^{53,54}$ and mixed 2D-3D perovskites. ${ }^{55}$ Such practices led to a jump in the PCE from 6\% in 2016 to around $9 \%,{ }^{55}$ and significantly enhanced stability. ${ }^{53}$ Zhao and coworkers adopted the cation mixing strategy to improve cell efficiency; by optimizing the ratio of the $\mathrm{FA}^{+}$and $\mathrm{MA}^{+}$cation mixture, a PCE of $8.12 \%$ was obtained along with an improved perovskite film morphology. ${ }^{51}$ Shao and co-workers mixed $92 \%$ of highly crystalline $3 \mathrm{D} \mathrm{FASnI}_{3}$ with $8 \%$ of $2 \mathrm{D}$ Sn perovskites in a $\mathrm{p}-\mathrm{i}-\mathrm{n}$ planar device; this increased the PCE to $9 \%$ with negligible hysteresis, low shunt losses, and very low trapassisted recombination. ${ }^{55}$ In early 2018, Ran and co-workers reported a 2D-3D heterojunction Sn-based PSC using phenylethylammoniumiodide (PEAI) as a $2 \mathrm{D}$ and $\mathrm{FASnI}_{3}$ as a $3 \mathrm{D}$ perovskite material and a PCE of $6.98 \%$ was obtained. ${ }^{56}$ At the same time, Liu and co-workers improved the morphology of perovskite layers by using hot antisolvent and annealing under a low partial pressure of DMSO. ${ }^{57}$ Both groups reported a PCE of around $7 \%$. In 2019, PCEs of Sn-based PSCs continued to surge, approaching the $10 \%$ threshold through two different approaches. Jokar and co-workers reported the first approach by using bulk organic molecules such as ethylenediammonium diiodide $\left(\mathrm{EDAI}_{2}\right)$ and butylammonium iodide (BAI) to improve film morphology and improve crystallinity in addition to surface passivation, and they achieved a PCE of $8.9 \% .{ }^{58}$ Later on, the same group used guanidinium cation $\mathrm{GA}^{+}$as a nonpolar organic cation mixed with an $\mathrm{FA}^{+}$cation in the ratio of $20: 80$ respectively in addition to $1 \%$ ethylenediammonium diiodide $\left(\mathrm{EDAI}_{2}\right)$ as an additive to suppress $\mathrm{Sn}$ (II) oxidation to $\mathrm{Sn}$ (IV) and passivate surface defects; $9.6 \%$ was achieved after storage in a glovebox environment for $2000 \mathrm{~h}$; this gradual increase in efficiency was attributed to the slow surface passivation and crystal relaxation. ${ }^{59}$ The second approach was reported by Wang and co-workers. They grew parallel-orientated 2D $\mathrm{PEA}_{2} \mathrm{SnI}_{4}$ on the surface of $3 \mathrm{D} \mathrm{FASnI}_{3}$, using pseudohalogen $\mathrm{NH}_{4} \mathrm{SCN}$ as a structure regulator. This hierarchical 2D-quasi2D-3D Sn-based perovskite structure delivered a PCE of $9.41 \%$ with improved air stability and high reproducibility. ${ }^{60}$ In 2020 , Nishimura and co-workers achieved a PCE of $13.24 \%$ by partially substituting $\mathrm{FA}^{+}$with ethylammonium $\left(\mathrm{EA}^{+}\right)$, which enhanced the film morphology and charge extraction. ${ }^{61}$ Recently, two high efficiencies were reported, $13.4 \%{ }^{62}$ using phenylhydrazine with FA as mixed cations and a mixture of
Table 1 Summary of the evolution of tin-based perovskite solar cells

\begin{tabular}{lllllll}
\hline & \multicolumn{5}{c}{ Photovoltaic parameters } & \\
\cline { 3 - 6 } Tin perovskite & Year & $V_{\text {oc }}[\mathrm{V}]$ & $J_{\text {sc }}\left[\mathrm{mA} \mathrm{cm}{ }^{-2}\right]$ & FF & PCE [\%] & Ref. \\
\hline MASnI $_{3}$ & 2014 & 0.88 & 16.8 & 42 & 6.4 & 15 \\
FASnI $_{3}$ & 2016 & 0.46 & 22 & 61 & 6.2 & 50 \\
FASnI $_{3}$ & 2017 & 0.53 & 24.1 & 71 & 9.0 & 55 \\
FASnI $_{3}$ & 2018 & 0.58 & 21.3 & 72 & 8.9 & 58 \\
FASnI $_{3}$ & 2018 & 0.61 & 22 & 70 & 9.4 & 60 \\
FASnI $_{3}$ & 2019 & 0.62 & 21.2 & 73 & 9.6 & 59 \\
FASnI $_{3}$ & 2020 & 0.84 & 20.3 & 78 & 13.2 & 61 \\
FASnI $_{2}$ Br & 2020 & 0.81 & 23 & 72 & 13.4 & 62 \\
FASnI $_{3}$ & 2021 & 0.91 & 20.6 & 77 & 14.6 & 63
\end{tabular}

halogens $\mathrm{Cl}^{-}$and $\mathrm{Br}^{-}$as mixed anions by Wang and co-workers; however, the record efficiency in tin perovskites is $14.63 \%$ using one-step synthesis of $\mathrm{SnI}_{2}$-solvent adducts. ${ }^{63}$ In terms of stability, Liu and co-workers reported $\mathrm{FASnI}_{3}$ layers prepared via templated crystal growth with a PCE of $11.22 \%$ and decent stability of over $1000 \mathrm{~h}$ of light soaking while retaining $95 \%$ of the initial efficiency. ${ }^{64}$ These improvements and efficiencies approaching $15 \%$ were possible through the big effort of the community. And, despite all the strategies implemented, Sn-based PSCs must still face important challenges if they are to reach the expected performance. The photovoltaic parameters of the best performing tin-based perovskite devices in recent years is summarized in Table 1.

In this review, we discuss the bottlenecks that hinder Sn-based PSCs from achieving efficiencies comparable to those of Pb-based PSCs. ${ }^{65}$ First, we discuss the effect of solvents and materials on the performance and stability of the devices and the recent efforts to find new solvent systems for $\mathrm{FASnI}_{3}$. Second, we discuss the film formation and crystallization dynamics in Sn-based perovskites and talk about the most effective tries to make oriented and highly crystalline films. In particular, we discuss the use of $2 \mathrm{D} / 3 \mathrm{D}$ mixed perovskites to make highly efficient Sn-based PSCs. After that, we discuss the oxidation of $\mathrm{Sn}$ (II) to $\mathrm{Sn}$ (Iv) and the most successful attempts to quench it. Finally, we discuss the energy band alignment and its effect on charge extraction and overall device efficiency.

\section{Precursors \& solvents}

To find the main reason behind the low efficiency in Sn-based halide perovskites, ${ }^{66}$ we have to take a step backward and follow up the processing steps from the beginning. We should start with the materials we use to prepare the precursor solutions. For example, commercially available reagents may contain a small but effective amount of $\mathrm{Sn}$ (Iv) $(<0.1 \%)$, which is enough to convert an $\mathrm{ASnX}_{3}$ film into a p-type material, with devastating effects on the photovoltaic performance of devices. ${ }^{67}$ Therefore, analyzing the purity of raw materials is necessary to guarantee that Sn(Iv) is not present as an initial component, minimizing the incorporation of oxidised species and alleviating self-p-doping. Furthermore, it is also vital for perovskite film formation, as we will explain in a later section. ${ }^{68}$ 
a)

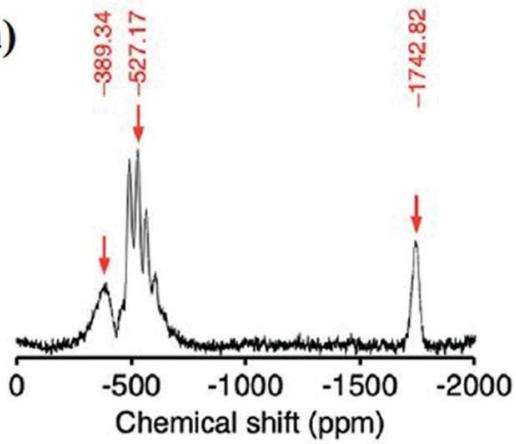

c)

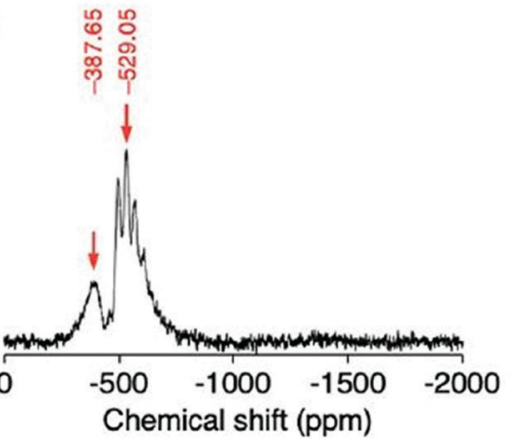

e)

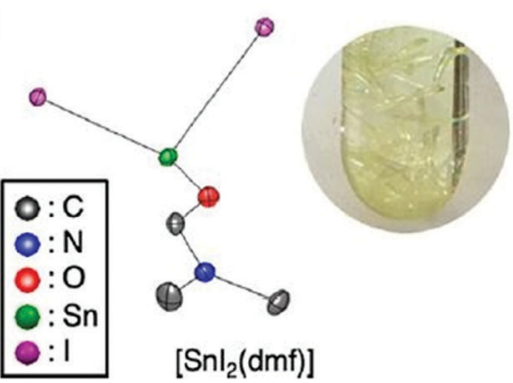

b)

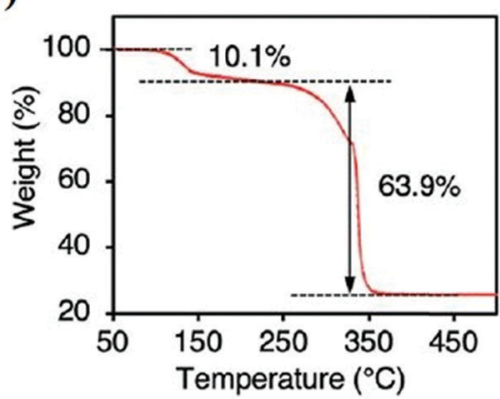

d)

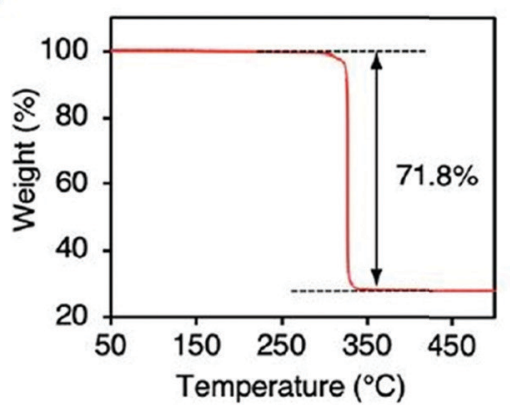

f)

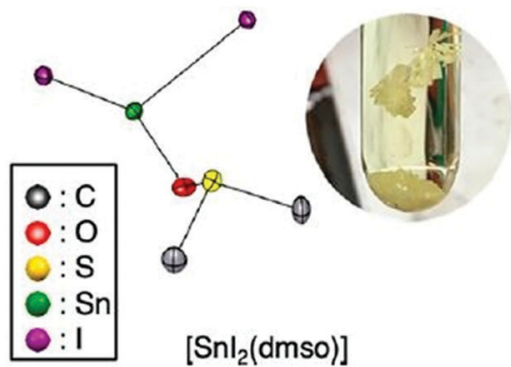

Fig. 2 Purified $\mathrm{Snl}_{2}$ reagents, (a and b) ${ }^{119} \mathrm{Sn} \mathrm{MAS} \mathrm{NMR} \mathrm{spectra,} \mathrm{and} \mathrm{TGA} \mathrm{analysis} \mathrm{of} \mathrm{commercially} \mathrm{purchased} \mathrm{Snl}_{2}$. (c and d) ${ }^{119} \mathrm{Sn}$ MAS NMR spectra and TGA analysis of purified $\mathrm{Snl}_{2}$ using the vacuum sublimation method. (e and f) Structural illustrations of [Snl ${ }_{2}(\mathrm{DMF})$ and $_{\text {[Snl }}$ (DMSO)]. ${ }^{69} \mathrm{Reproduced} \mathrm{with}$ permission Copyright 2020, American Chemical Society.

Several researchers placed great importance on material purification, and different approaches were reported. Ozaki and co-workers followed a chemical purification strategy in which they formed a tin halide-solvent complex $\left[\operatorname{SnX}_{2}(\mathrm{~S})_{n}\right]$ where $\mathrm{S}$ is a solvent ( $\mathrm{S}=\mathrm{DMF}$ and DMSO) ${ }^{69,70}$ In the beginning, they characterized $\mathrm{SnI}_{2}$ using ${ }^{119} \mathrm{Sn}$ magic-angle spinning (MAS) NMR spectroscopy, thermogravimetric analysis (TGA), and Karl Fischer titration. They found that $\mathrm{SnI}_{2}$ contains around $10 \%$ of $\mathrm{SnI}_{4}$ and about $10000 \mathrm{ppm}$ of water, although the bottle was labeled $99.99 \%$ purity. The ${ }^{119}$ Sn-NMR spectra in Fig. 2 a show a peak at $-1742 \mathrm{ppm}$, which is attributed to the $\mathrm{SnI}_{4}$. TGA confirmed the same results as $10.1 \%$ weight loss was observed at $\sim 150{ }^{\circ} \mathrm{C}$, which corresponds to the sublimation of $\mathrm{SnI}_{4}$ (Fig. 2b), while $\mathrm{SnI}_{2}$ sublimates at $330{ }^{\circ} \mathrm{C}$. Next, Ozaki and co-workers utilized the difference in the sublimation temperature between $\mathrm{SnI}_{2}$ and $\mathrm{SnI}_{4}$ to purify $\mathrm{SnI}_{2}$ using the vacuum sublimation technique where $\mathrm{SnI}_{4}$ sublimates and then condensates as an orange powder at $\sim 150{ }^{\circ} \mathrm{C} .{ }^{69}{ }^{119} \mathrm{Sn}-\mathrm{NMR}$ and TGA analyses of the purified $\mathrm{SnI}_{2}$ using the vacuum sublimation method are shown in Fig. $2 \mathrm{c}$ and $\mathrm{d}$.
They recrystallized $\mathrm{SnI}_{2}$ in DMF and DMSO to remove any $\mathrm{SnO}_{2}$ residuals from the vacuum sublimation step for further purity. $\mathrm{SnI}_{2}$ from the first step was dissolved in DMF and DMSO, and then toluene or dichloromethane was poured gently into the solution, which converted into needle crystals of $\left[\mathrm{SnI}_{2}(\mathrm{DMSO})\right],\left[\mathrm{SnI}_{2}(\mathrm{DMSO})_{2}\right]$ and $\left[\mathrm{SnI}_{2}(\mathrm{DMF})\right]$ as determined by single-crystal XRD (Fig. 2e and f). The purity of these crystals was confirmed using elemental analysis and ${ }^{119}$ Sn MAS NMR spectroscopy and found to be stable under an inert atmosphere and could be used conveniently as a pure starting reagent for tin perovskites. The authors merged these purifying techniques with other film formation methods and additives to achieve a PCE of $\sim 12 \%$ for $\mathrm{FASnI}_{3}$.

Solvents have a very strong influence on perovskite film crystallization and, hence, on the device performance. ${ }^{71,72}$ Nevertheless, in Sn-based PSCs, solvents have a much more profound influence due to the sensitivity of $\mathrm{Sn}$ (II) towards oxidation. ${ }^{73}$ In parallel, Sargent's group and our group independently found that DMSO was undergoing a redox reaction 
with $\mathrm{Sn}$ (II), oxidizing it to $\mathrm{Sn}(\mathrm{IV}) .{ }^{74,75}$ Solid-state ${ }^{119} \mathrm{Sn}$-NMR analysis of the received $\mathrm{SnI}_{2}$ did not show any $\mathrm{Sn}(\mathrm{IV})$ peaks, implying no content of it or a concentration lower than the measured detection limit of $1.5 \mathrm{wt} \%$. By exposing the same sample to air, the Sn(Iv) signal appeared and increased with exposure to air. After that, fresh precursor solutions of $\mathrm{FASnI}_{3}$ were prepared and characterized for the presence of $\mathrm{Sn}$ (Iv). Fortunately, there was no $\mathrm{Sn}$ (Iv) at room temp, but after heating the solutions at $100{ }^{\circ} \mathrm{C}$ for 30 minutes to simulate the conditions of the film formation, the color of the DMSO-based FASnI $_{3}$ changed to dark red, and Sn(Iv) peaks were detected in the ${ }^{119} \mathrm{Sn}$-NMR spectrum. ${ }^{75}$ To further understand the oxidation mechanism of $\mathrm{Sn}$ (II) to $\mathrm{Sn}(\mathrm{Iv}),{ }^{13} \mathrm{C}-\mathrm{NMR}$ and ${ }^{1} \mathrm{H}-\mathrm{NMR}$ analyses were performed for the organic species in precursor solutions (DMSO, FAI, and MAI). ${ }^{1} \mathrm{H}-\mathrm{NMR}$ showed a peak at $\sim 1.9$ ppm for both $\mathrm{MA}^{+}$and $\mathrm{FA}^{+}$containing solutions, and this peak matches with the expected peak of dimethylsulphide (DMS) which confirms the same finding reported earlier by Saidaminov and co-workers. The same peak was found in the ${ }^{13} \mathrm{C}$-NMR spectrum, which confirms the formation of DMS as a product of the $\mathrm{Sn}$ (II) oxidation reaction (Fig. 3b). Previous results confirm the occurrence of a redox reaction between DMSO and Sn(II) which is promoted in the presence of an acidic environment ${ }^{76,77}$ (Fig. 3c).

Considering the negative impact of DMSO, so far the universal solvent for tin perovskites, on material stability, our group decided to replace it by new solvent combinations. ${ }^{78}$ We targeted solvents with the ability to form a perovskite solution with a concentration over $1 \mathrm{M}$ and be stable after thermal soaking for at least 12 hours at $100{ }^{\circ} \mathrm{C}$. For this, we screened most of the possible functional groups with particular attention to dipolar aprotic solvents which could dissolve ionic molecules such as FAI and $\mathrm{SnI}_{2}$ using their strong dipoles. Some solvents were excluded, such as strong acids, solvents with big aromatic structures commonly used as antisolvents, solvents with too low boiling point such as methylamine, and solvents with a high melting point. Out of 2000 suggested molecules, we tested 76 solvents for their solubility, stability, and ability to form a perovskite solution. Experimentally, we identified 12 solvents that could form a stable perovskite solution with six different functional groups with the amide group being the mostly presented (Fig. 4a). To ensure that these new precursors could form perovskite materials, the easiest way was to drop-cast the precursor on a glass substrate, and then anneal at $150{ }^{\circ} \mathrm{C}$ for 20 minutes with a thermal ramp of $12{ }^{\circ} \mathrm{C}$ $\min ^{-1}$. It was impressive that 15 out of 17 solvents (including DMSO and DMF) formed a black phase. XRD characterization was performed for the drop-casted films of the new solvents, and the resultant peak positions are in agreement with the standard positions of crystalline $\mathrm{FASnI}_{3}$ films. However, some samples have low crystallinity, and some other samples have different phases; such optimizations can be dealt with in the film formation stage.

The ability of the new solvents to form a working perovskite device was also tested. A mixture of two solvents, namely $N, N$-diethylformamide (DEF) and $N, N^{\prime}$-dimethylpropyleneurea a)

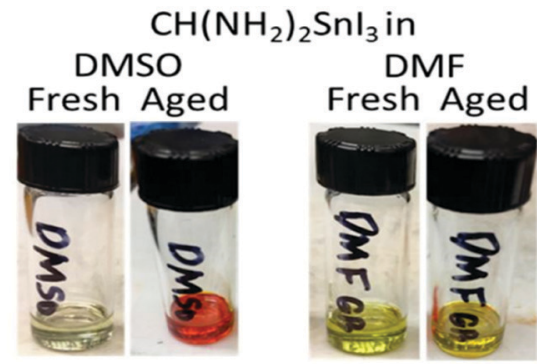

b)

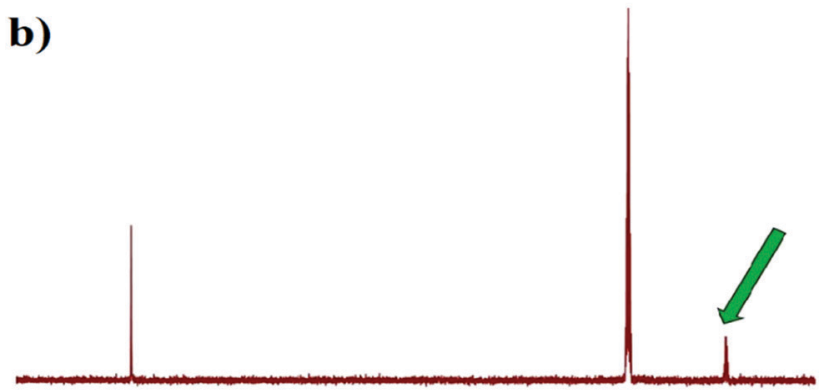

$\begin{array}{llllllllllllllllllllllllllll}180 & 170 & 160 & 150 & 140 & 130 & 120 & 110 & 100 & 90 & 80 & 70 & 60 & 50 & 40 & 30 & 20 & 10 & 0\end{array}$ $\delta(\mathrm{ppm})$

c)

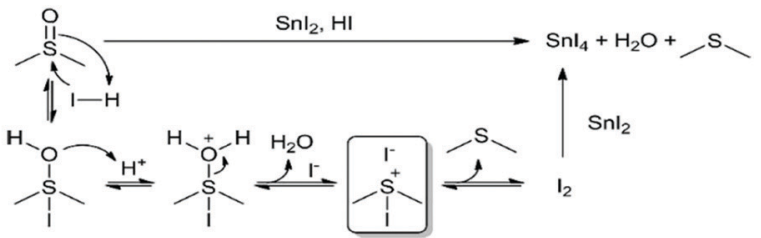

Fig. 3 Oxidative effect of DMSO, (a) $\mathrm{FASnl}_{3}$ solutions in DMSO and DMF before and after ageing for $5 \mathrm{~h}$ at $120{ }^{\circ} \mathrm{C} .{ }^{74}$ Reproduced with permission Copyright 2020, American Chemical Society. (b) Mechanism of Sn(॥) oxidation by DMSO. (c) ${ }^{13} \mathrm{C}$-NMR spectra of $\mathrm{FASnl}_{3}$ heated at $100{ }^{\circ} \mathrm{C}$ for $30 \mathrm{~min}$. The green arrow indicates the DMS-related peak. ${ }^{75}$ Reproduced with permission, Copyright 2021, The Royal Society of Chemistry.

(DMPU), in a 6:1 ratio achieved a PCE of 6.2\% for $\mathrm{FASnI}_{3}$ without using any additives. Meanwhile, additive-free DMSO samples achieved a PCE of only $3.84 \%$ (Fig. $4 \mathrm{~b}$ and c). These results prove that finding a new stable solvent for processing Sn-based perovskites could be an entrance towards achieving highly efficient and durable tin-based PSCs.

\section{Film formation}

The formation of high-quality perovskite films is a vital prerequisite to push the performance of PSCs forward. ${ }^{79}$ The crystalline quality and morphology of perovskite films are related directly to the overall performance of the device. To make high-quality perovskite films, we have to understand and manipulate the mechanism of crystal formation that starts from the precursor solution and ends at the end of the annealing step. ${ }^{80}$ The perovskite crystallization process depends on several factors such as the substrate nature, temperature, spin coating parameters, solvent, and antisolvent interaction. ${ }^{81}$ Film formation dynamics and crystallization kinetics in Sn-based perovskites are different from those of lead-based perovskites. ${ }^{82}$ 
a)

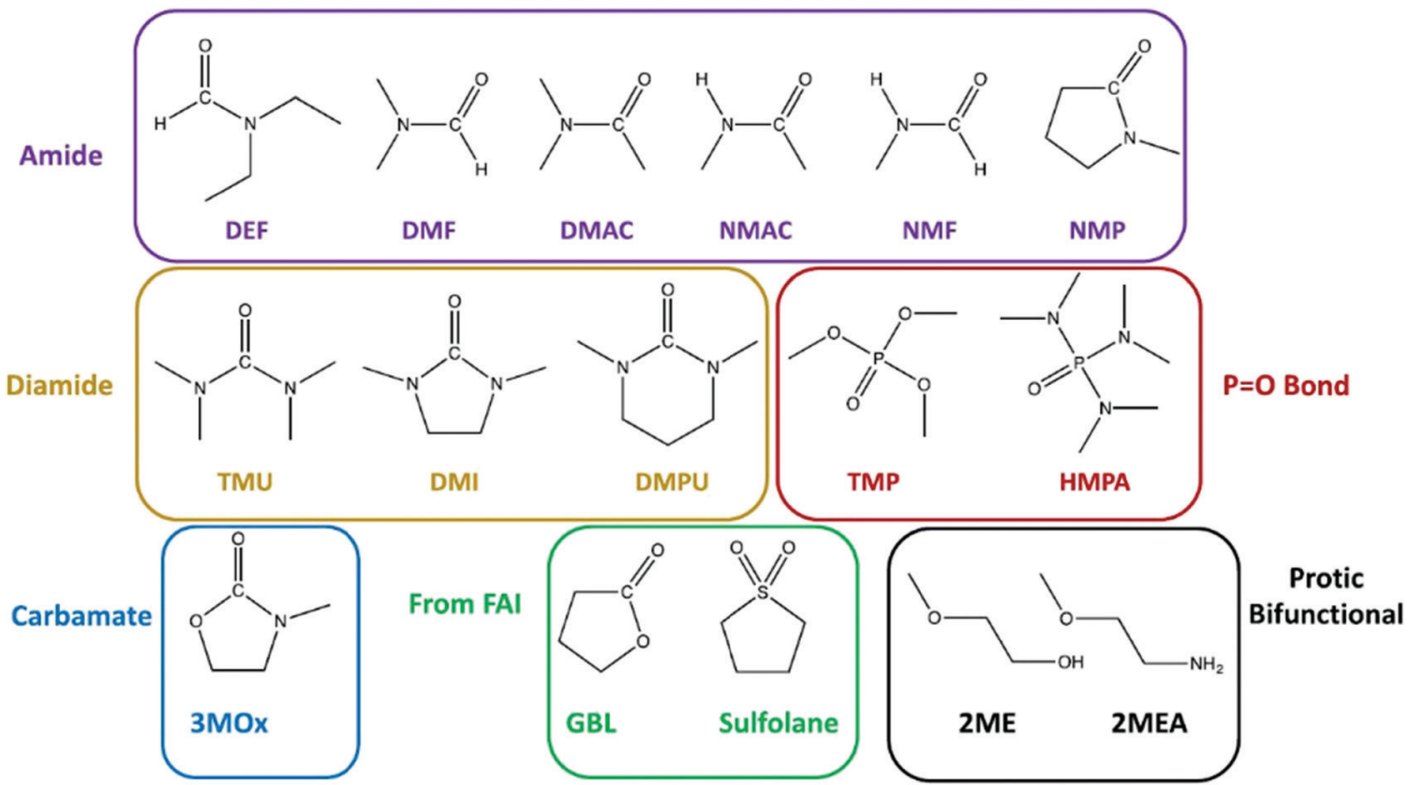

b)

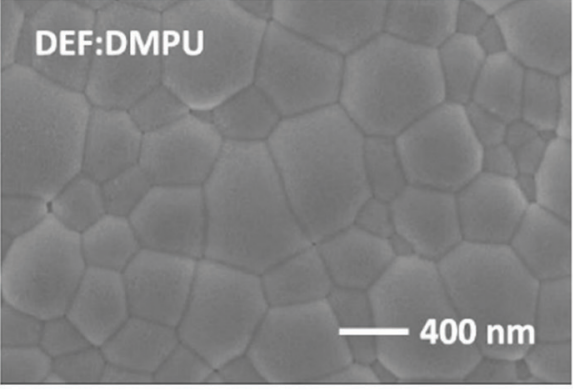

c)

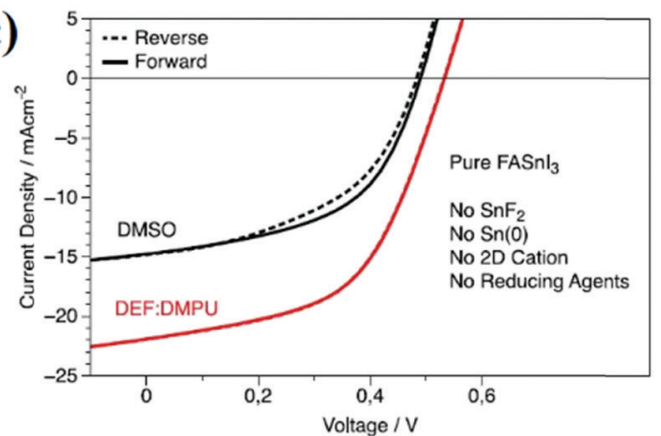

Fig. 4 (a) 16 nonsulfoxide solvents that formed stable perovskite solution divided into groups according to the functional group. (b) SEM images of the DEF:DMPU film. (c) J-V curves of FASnl 3 without any additives in DEF:DMPU against DMSO ${ }^{78}$ Reproduced with permission Copyright 2021, American Chemical Society.

Although many reports focused on studying the crystallization dynamics and kinetics of $\mathrm{Pb}$-based perovskites through in situ techniques, ${ }^{82,83}$ very few reports dealt with the same point in Sn-based perovskites. Dong and co-workers studied the crystallization mechanism of tin perovskites using several techniques, offering essential insights that revealed the mechanism of structural revolution, material transformation, and crystallization dynamics in mixed 2D/3D Sn-based perovskites. ${ }^{84}$ They found that crystallization tends to start at the precursor/air interface, but in 3D Sn-based perovskites, the crystallization rate is comparable in bulk and at the precursor/air interface. Moreover, the addition of $2 \mathrm{D}$ molecules hinders the crystallization process in bulk, which allows uniform and highly oriented crystals with a similar structure to the 3D perovskites. The crystallization dynamics, in general, were found to be very fast compared to the lead-based counterpart.

The attempts to optimize the quality of Sn-based perovskite films are numerous. Most of them rely on chemical additives that could form 2D perovskites on top of the regular 3D perovskite layer, usually known as Ruddlesden-Popper perovskites. ${ }^{60,85,86}$
Liu and co-workers reported a PCE of $11.22 \%$ based on highly crystalline $\mathrm{FASnI}_{3}$ films with preferential orientation along the (001) plane. ${ }^{64}$ They reported a solvent pretreatment method using a mixture of $n$-propylammoniumiodide (PAI) and DMSO $(1: 100 \mathrm{v} / \mathrm{v})$. DMSO acts as a solvent to provide the liquid interface for nucleation. At the same time, PAI aggregates around the newborn nuclei of $\mathrm{FASnI}_{3}$ and forms a template that regulates the crystal growth and orients it along the (100) plane. PAI was used in a minimal amount compared to DMSO $(1: 100 \mathrm{v} / \mathrm{v})$ as it is not considered as an additive to the precursor solution or co-solvent because it is not forming $2 \mathrm{D}$ perovskite that covers the surface of $3 \mathrm{D}$ perovskites. The mechanism of action of PAI is shown in Fig. 5a. SEM images in Fig. $5 \mathrm{~b}$ indicate a big difference in the grain sizes between FASnI $_{3}$ with and without PAI. The bigger the grain and the domains, the less the grain boundaries and the less the defects. In templated growth $\mathrm{FASnI}_{3}$ (TG-FASnI ${ }_{3}$ ), the defect density was lowered from $2.89 \times 10^{16} \mathrm{~cm}^{-3}$ to $5.41 \times$ $10^{15} \mathrm{~cm}^{-3}$. The XRD patterns in Fig. $5 \mathrm{c}$ show an increasing intensity of the 100 plane peak with an increase in the 
a)

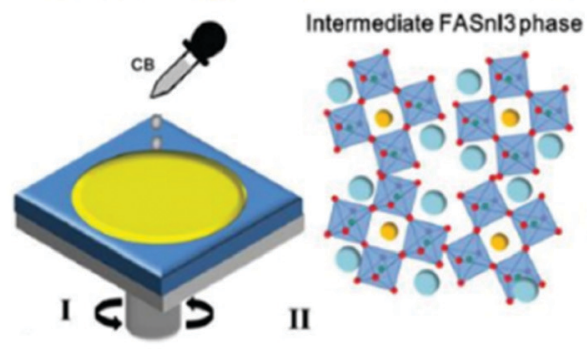

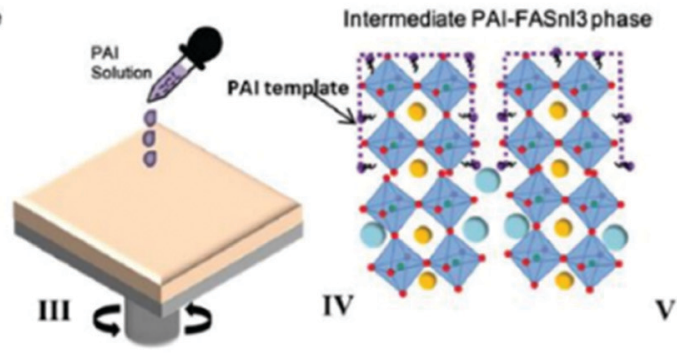

PAI-FASnl3 film

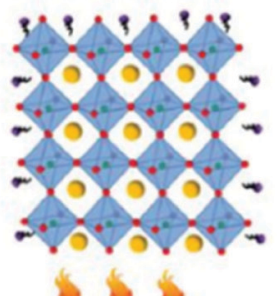

b)
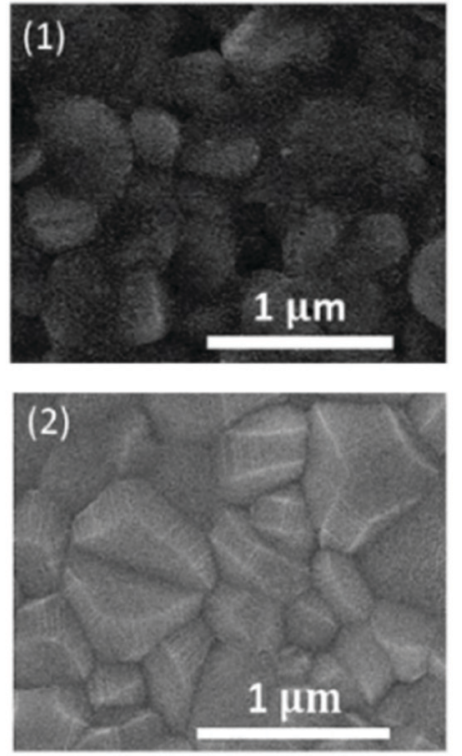

e)

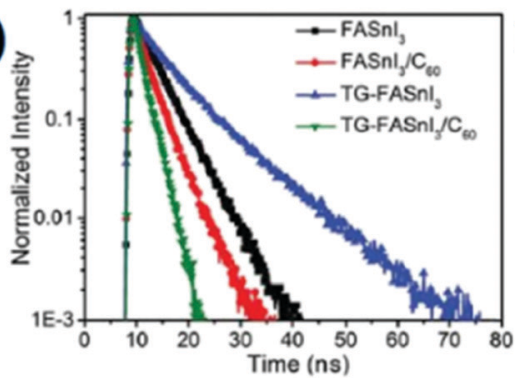

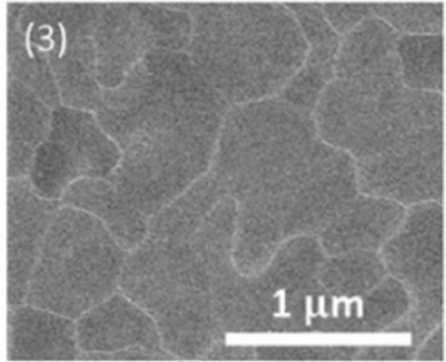

c)
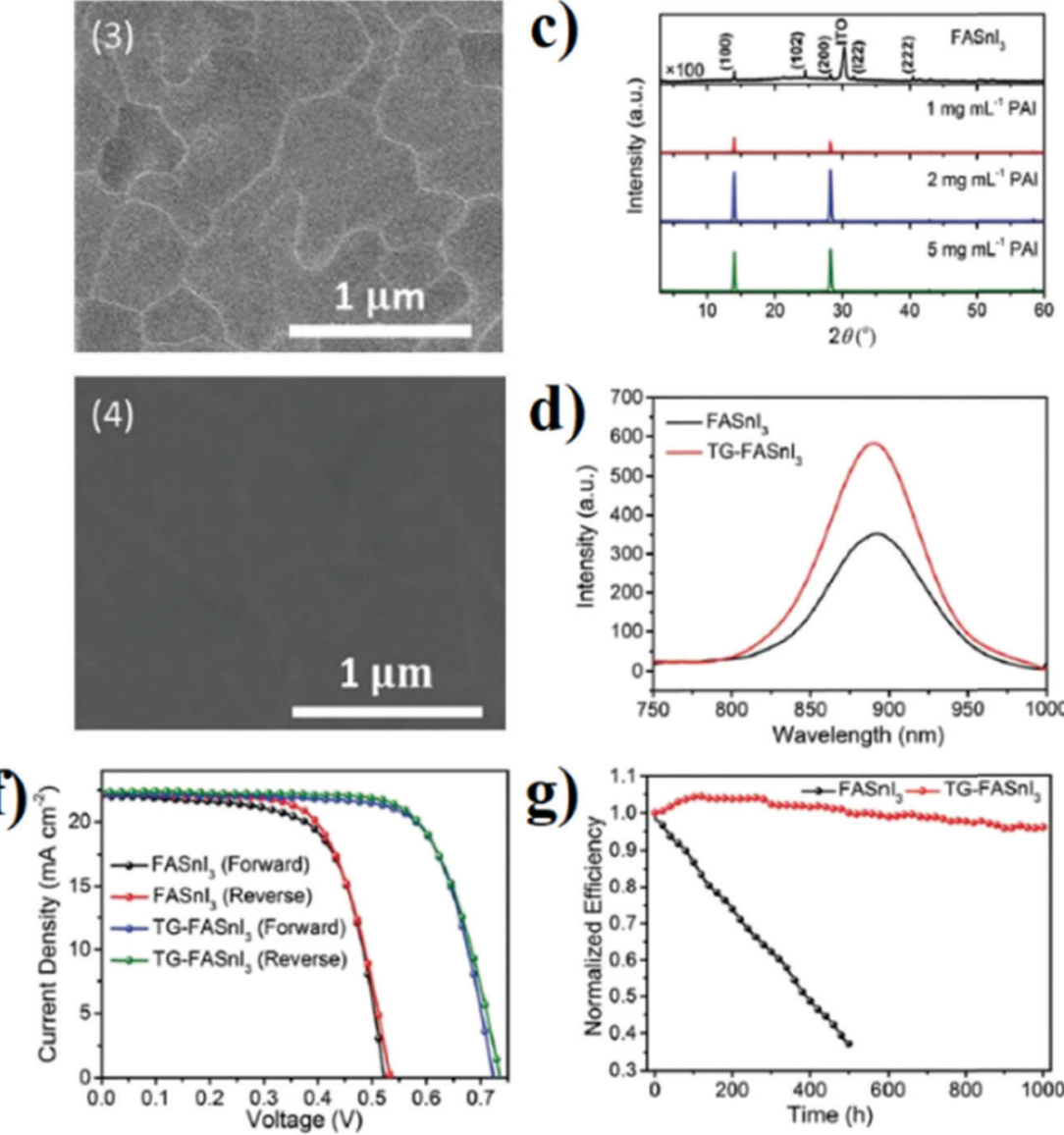

d)

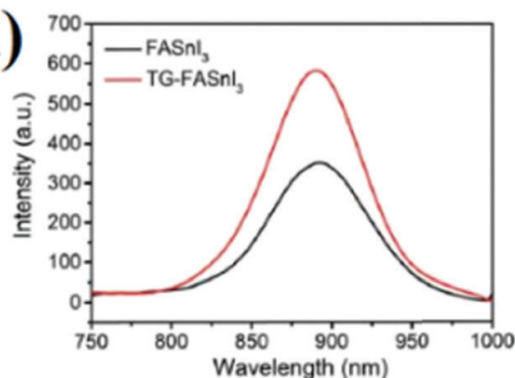

g)

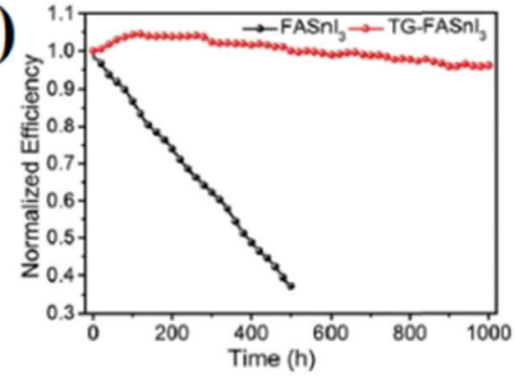

Fig. 5 (a) Proposed mechanism of action of TG-FASnl 3 . (b) SEM images of FASnl 3 (1) before and (2) after annealing; TG-FASnl (3) before and (4) after annealing. (c) XRD patterns of FASnl 3 and TG-FASnl 3 . (d) PL spectra of FASnl 3 and TG-FASnl 3 . (e) TRPL of FASnl ${ }_{3}$ and TG-FASnl 3 . (f) J-V curves of FASnl 3 and TG-FASnl 3 in forward and reverse scanning. (g) Stability test of FASnl 3 and TG-FASnl 3 under simulated AM $1.5 \mathrm{G}\left(100 \mathrm{~mW} \mathrm{~cm}^{-2}\right.$ ) operating at MPPT. ${ }^{64}$ Reproduced with permission, Copyright 2020, The Royal Society of Chemistry.

concentration of PAI from 1 to $2 \mathrm{mg} \mathrm{mL}^{-1}$, while it decreases again after increasing the concentration to $5 \mathrm{mg} \mathrm{mL} \mathrm{mb}^{-1}$, which indicates that the optimum concentration of PAI is around $2 \mathrm{mg} \mathrm{mL} \mathrm{m}^{-1}$. The effect of such a small quantity of PAI on the crystallization and the photovoltaic performance of $\mathrm{FASnI}_{3}$ was tremendous as shown in Fig. 5d-g. TG-FASnI ${ }_{3}$ shows an increase in PL intensity which confirms the low defect density and the longer carrier diffusion length than regular control FASnI $_{3}$. The prepared devices based on TG-FASnI ${ }_{3}$ showed much better operational stability compared to the control devices. Fig. $5 \mathrm{~g}$ shows the results of maximum power point tracking (MPPT) of both devices encapsulated and stored in an $\mathrm{N}_{2}$ filled glove box. $95 \%$ of the initial efficiency was maintained after $1000 \mathrm{~h}$ of operation, while the control devices lost around $60 \%$ of their initial efficiency after $500 \mathrm{~h}$.

Finally, one of the bottlenecks that tin-based perovskites face is the fast crystallization leading to low film quality compared to that of lead-based perovskites, which leads to a high defect density in the range of $10^{15}-10^{16}$, while in leadbased perovskites, it is $10^{13}-10^{14} \mathrm{~cm}^{-3}$. This high defect density is one of the main reasons behind the low efficiency of tin-based perovskites. ${ }^{87}$ 


\section{Sn(II) oxidation}

Oxidation of $\mathrm{Sn}$ (II) is one of the bottlenecks to achieve good efficiency in Sn-based perovskites solar cells. Sn(II) is more vulnerable to oxidation which is electronically and chemically favorable. ${ }^{88}$ It has been revealed through theoretical calculations that tin oxidation is favorable on the pristine surface and unfavorable in the bulk. Resultantly, bulk Sn(Iv) changes into $\mathrm{Sn}$ (II), which releases two holes to the valence band and by p-doping the perovskite, ${ }^{68}$ this has been experimentally proved that tin vacancies lead to $\mathrm{p}$-doping which limits the diffusion length. ${ }^{15,89}$

Although $\mathrm{Sn}$ and $\mathrm{Pb}$ are present in the same group of the periodic table, it has been found that the $S n 5 \mathrm{~s}^{2}$ orbital has higher energy as compared to the $6 \mathrm{~s}^{2}$ orbital of $\mathrm{Pb}$ which increases its contribution to the valence band edge. The electrons of $6 \mathrm{~s}^{2}$ in $\mathrm{Pb}$ show an inert pair effect due to lanthanide contraction but $5 \mathrm{~s}^{2}$ lacks this phenomenon which ultimately makes Sn electrons loosely bound and easy to lose. ${ }^{90}$

To stop the oxidation of tin and to improve the stability of the perovskite films and devices, different $\mathrm{SnX}_{2}$ species have been employed in excess to stop p-doping. For the first time, Kumar and co-workers showed that the introduction of $\mathrm{SnF}_{2}$ in inorganic tin halide $\mathrm{CsSnI}_{3}$ reduces the $\mathrm{Sn}$ vacancies. ${ }^{91}$ Later on, they have also reported that by the introduction of $\mathrm{SnF}_{2}$ in $\mathrm{FASnI}_{3}$ films, the oxidation of $\mathrm{Sn}(\mathrm{II})$ has been effectively reduced, and there is an increase in the $J_{\mathrm{sc}}$ values of the device. ${ }^{92} \mathrm{SnF}_{2}$ has also been introduced in $\mathrm{CsSnBr}_{3}$ films, and it has been found that it suppresses the oxidation of $\mathrm{Sn}$ (II). ${ }^{93}$ In the most recent work on Sn halide perovskite-based devices, $\mathrm{SnF}_{2}$ has been used as an important dopant as it suppresses the oxidation of $\mathrm{Sn}(\mathrm{II})$, improves film morphology, and also improves $J_{\mathrm{sc}}{ }^{94}$ Other $\mathrm{SnX}_{2}$ species like $\mathrm{SnCl}_{2}, \mathrm{SnBr}_{2}$ and $\mathrm{SnI}_{2}$ improve the film quality, device performances ${ }^{95}$ energy alignments ${ }^{91}$ and also surface passivation. ${ }^{96}$

Hydrazine and its derivatives were used by many researchers as a reducing material in Sn-based perovskites. Hydrazine in the vapor phase has been used in $\mathrm{MASnI}_{3}$ and $\mathrm{CsSnI}_{3}$ film formation and for device fabrication. ${ }^{97}$ The ratio of $\mathrm{Sn}$ (Iv) to $\mathrm{Sn}$ (II) has been reduced by using hydrazine vapors. It has been found that hydrazine molecules release electrons which suppress the oxidation of $\mathrm{Sn}(\mathrm{II}) .{ }^{98}$ By introducing phenylhydrazine hydrochloride salt $(\mathrm{PHCl})$ in the $\mathrm{FASnI}_{3}$ film, Wang and co-workers reported $11.4 \%$ efficiency. It has been noticed that incorporating the molecules in the crystal lattice improves the device performance. ${ }^{99}$ Similarly, by adding $8 \mathrm{~mol} \%$ trihydrazine dihydriodide (THDH) to $\mathrm{FASnI}_{3}$ solution, the oxidation of $\mathrm{Sn}$ (II) was suppressed, and the champion device efficiency was reported to be $8.50 \%$. Another derivate of hydrazine 4-fluorobenzohydrazide (FBH) was introduced in $\mathrm{FASnI}_{3}$, and it significantly enhanced the efficiency as compared to that of the control device. The champion device efficiency was reported to be $9.03 \%$ by using FBH molecules. ${ }^{100}$ Recently, Wang and co-workers achieved a record efficiency of $13.4 \%$ (12.4\% certified) through the introduction of synergistic effects between $\mathrm{PH}$ cations and halide anions. ${ }^{62}$
T. Wang and co-workers introduced gallic acid (GA) as an antioxidant along with $\mathrm{SnCl}_{2}$ for $\mathrm{FASnI}_{3}$ films. By exploring the underlying chemistry of GA and the tin precursor, they reported 9.03\% efficiency. ${ }^{101}$ Kayesh and co-workers used 5-ammonium valeric acid (5-AVAI) to enhance the oxidation stability of $\mathrm{FASnI}_{3}$ perovskite films. 5-AVAI not only suppresses the Sn(II) oxidation but also enhances the crystallinity by making a hydrogen bond with $\mathrm{SnI}_{6}$. The devices show improved stability with $7 \%$ efficiency. ${ }^{102}$

The primary precursor used for tin halide perovskites is $\mathrm{SnI}_{2}$. It is oxidized by air. To make it purer, Sn metal powder is used. Low purity has a high level of doping which ultimately decreases the efficiency. Huang and co-workers used tin powder to purify tin sources from Sn(rv) moieties, which has increased the device performance parameters. ${ }^{103}$ Recently, Nakamura and co-workers have reported a different technique to make $\mathrm{Sn}(\mathrm{Iv})$ free devices. They have produced $\mathrm{Sn}$ metal nanoparticles from $\mathrm{SnF}_{2}$ over $\mathrm{SnBr}_{2}$ and $\mathrm{SnCl}_{2}$ by using 1,4-bis(trimethylsilyl)2,3,5,6-tetramethyl-1,4-dihydropyrazine (TM-DHP) molecules. These Sn metal nanoparticles can reduce $\mathrm{SnI}_{4}$ to $\mathrm{SnI}_{2}$ to make it a $\mathrm{Sn}$ (Iv) free system. By using this technique, they have reported more than $11.2 \%$ certified efficiency. ${ }^{104}$

\section{Device structure and energy alignment}

In device operation, when light is shone on the device, due to the low bandgap, the electrons from the valence band of the perovskite halide materials shift to the conduction band and leave the hole vacancies in the valence band. These generated electrons and holes diffuse in the ETM and HTM and are finally collected at the cathode and anode. These ETM and HTM materials should be efficient enough to transport the electrons and holes across the boundary. This phenomenon is only possible when the highest occupied molecular orbitals (HOMO) and lowest unoccupied molecular orbitals (LUMO) of the hole transport material and electron transport layer are well aligned with the conduction and the valence band of the perovskite material. For better performance and stability of the devices, hole transport materials and electron transport layers are chosen accordingly. ${ }^{105}$

Conventional HTMs in Sn-based perovskites were designed originally for Pb-based perovskites and then tried for Sn-based devices after showing a good performance. However, the positions of energy bands in Sn-based perovskites are slightly different from those of $\mathrm{Pb}$-based perovskites. This leads to mismatching in the alignment of the energy bands of the absorber material with charge transfer layers on both sides of the Sn-based absorber film. ${ }^{106}$ For instance, the conventional HTM used in inverted devices poly(3,4-ethylenedioxythiophene): poly(styrenesulfonate) (PEDOT:PSS) has a work function of about

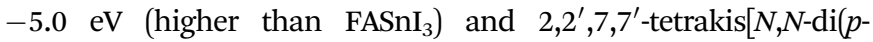
methoxyphenylamine)]-9,9-spirobifluorene (spiro-OMeTAD) has an even more higher HOMO level that is $-5.22 \mathrm{eV}$. Due to these 
(a)

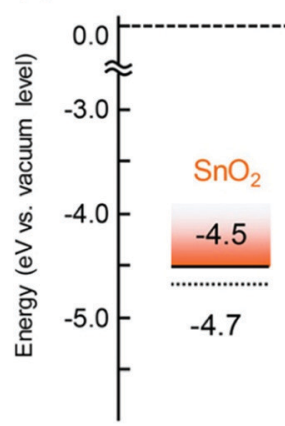

(b)

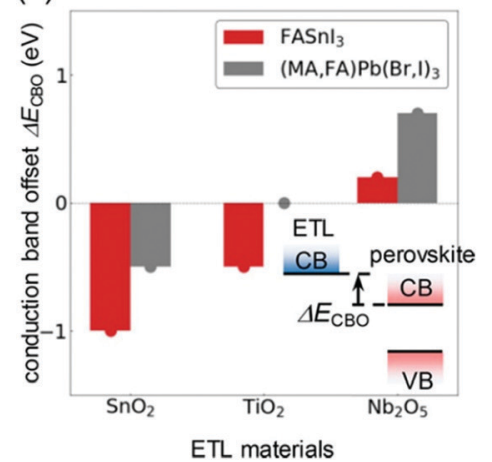

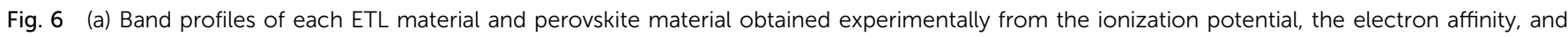

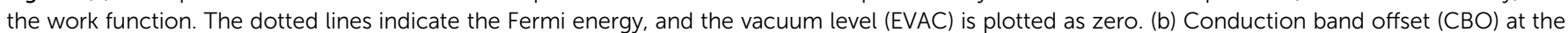

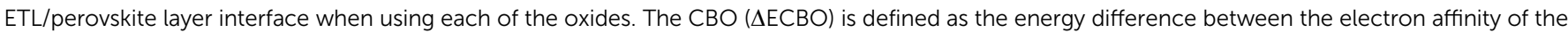

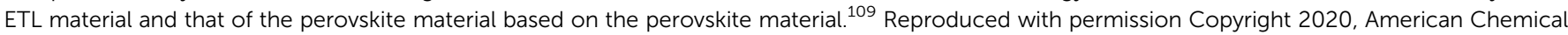
Society.

poor energy alignments, Sn-based PSCs are unable to achieve their theoretical predicted efficiency.

Initially, Noel and co-workers have reported Sn-based perovskite halide-based regular devices with efficiencies of greater than $6 \%$ under simulated full sunlight using $\mathrm{MASnI}_{3}$ as a perovskite material. Later on, it was found that spiro-OMeTAD, which is used as the hole transport material in regular structure devices, needs dopants like lithium bis(trifluoromethanesulfonyl)imide (Li-TFSI) and 4-tert-butylpyridine ( $t \mathrm{BP})$, which enhance its hole mobility. These dopants have a harmful effect on the perovskite layer ${ }^{107}$ and in addition to that, they increase the rate of charge recombination by forming bonds between $\mathrm{TiO}_{2}$ and Sn (Fig. 6). ${ }^{108}$

After these attempts, the first inverted device reported 3.30\% efficiency, which was fabricated by using $\mathrm{CsSnI}_{3}$ as the perovskite material, $\mathrm{NiO}_{x}$ as the hole transport layer, and PCBM and $\mathrm{Al}$ as ETLs. By using PEDOT:PSS as the HTL, Liao and co-workers reported $6.22 \%$ efficiency. ${ }^{50}$ Later on, Liu and co-workers tuned the energy levels of PEDOT:PSS by using polyethylene glycol (PEG). Fullerene molecules are used as ETMs in inverted devices. To know which derivative has the best energy alignment with Sn perovskites. $\mathrm{C}_{60}$, PCBM, and ICBA were used as ETLs for $\mathrm{FA}_{0.9} \mathrm{PEA}_{0.1} \mathrm{SnI}_{3}$. Among all, ICBA with work functions of -3.73 and -5.73 has perfect energy alignment with the perovskite and has a higher $V_{\mathrm{oc}}$ value as compared to others. Due to the dopant issues in spiroOMETAD, Ke and co-workers reported dopant-free organic molecules such as tetrakis-triphenylamine (TPE) as the HTM for Sn-based PSCs, and they reported $7.23 \%$ champion device efficiency. ${ }^{110}$ Similarly, due to the shortcomings of PEDOT:PSS, Cao and co-workers introduced copper thiocyanate (CuSCN) as the HTM for the $\mathrm{FASnI}_{3}$ based device and acquired $7.34 \%$ efficiency. ${ }^{111}$ The conventional electron transport layer in a $\mathrm{Pb}$-based perovskite solar cell has an energy mismatch with that of a Sn halide-based perovskites solar cell. Yokoyama and co-workers used $\mathrm{Nb}_{2} \mathrm{O}_{5}$ as the electron transport material in place of $\mathrm{TiO}_{2}$ in a regular inverted device. It has been found that it decreased the conduction offset and interfacial charge recombinations. ${ }^{109}$

This study reveals that the conduction band of $\mathrm{Nb}_{2} \mathrm{O}_{5}$ is closest to zero for $\mathrm{FASnI}_{3}$ perovskite materials; this increases the $V_{\text {oc }}$ of Sn PSCs as compared to that of $\mathrm{TiO}_{2}$ and $\mathrm{SnO}_{2}$. To gain a good energy alignment, Cong and co-workers introduced an organic molecule poly[tetraphenylethene3,3'-(( (2,2-diphenylethene-1,1-diyl)bis(4,1-phenylene))bis(oxy)) bis ( $N, N$-dimethylpropan-1-amine)tetraphenylethene] (PTN-Br) in $\mathrm{FASnI}_{3}$ to modify grain boundaries. It has the highest occupied molecular orbital (HOMO) energy level of $-5.41 \mathrm{eV}$, due to which it forms an energy alignment with the Sn halide perovskites solar cell. ${ }^{112}$ Precise measurements of the energy levels of tin-based perovskites were provided by Shuxia and co-workers. ${ }^{106}$ These values are beneficial for making a new cascade route for electrons and holes.

\section{Conclusion and outlook}

Sn-based PSCs carry enough optoelectronic properties to achieve the maximum theoretical efficiency of a single junction solar cell according to the QS limit. We believe that it will also be a key component in the multi-junction solar cell industry. So far, an efficiency of $14.6 \%$ has been achieved, which is $10 \%$ less than where it should be compared to those of Pb-based PSCs. However, to achieve such ambitious goals, Sn-based PSCs must overcome four bottlenecks, namely: (1) pure starting chemicals and non-oxidising solvents, (2) better film formation dynamics, (3) Sn(II) oxidation suppression and (4) better energy band alignment. To overcome these limitations, we need to focus on finding new, stable, and effective solvents for Sn-based PSCs. We also need to understand the Sn chemistry inside the precursor, and through film formation steps, customize new contact layers that have better matching with the energy bands of Sn-based compositions, and stabilizing Sn(II) through all the device making steps. Then we could provide a high 
protection and isolation level to devices under operation using modern encapsulation techniques. ${ }^{113,114}$

\section{Conflicts of interest}

There are no conflicts of interest to declare.

\section{Acknowledgements}

M. A. and Z. I. thank DAAD and Egyptian missions for PhD scholarship. The authors acknowledge financial support from the Natural Science Foundation of China (No. 51903181). G. L. thanks China Scholarship Council (CSC) for financial support (Grant No. 201906150131). Authors thanks the Distinguished Scientist Fellowship Program (DSFP) at KSU for financial support.

\section{References}

1 A. Kojima, K. Teshima, Y. Shirai and T. Miyasaka, Organometal Halide Perovskites as Visible-Light Sensitizers for Photovoltaic Cells, J. Am. Chem. Soc., 2009, 131, 6050-6051.

2 NREL, Best Research-Cell Efficiencies, https:/www.nrel. gov/pv/assets/pdfs/best-research-cell-efficiencies-190416. pdf, accessed 18 June 2019.

3 A. K. Jena, A. Kulkarni and T. Miyasaka, Halide Perovskite Photovoltaics: Background, Status, and Future Prospects, Chem. Rev., 2019, 119, 3036-3103.

4 J. Gong, M. Flatken, A. Abate, J.-P. Correa-Baena, I. MoraSeró, M. Saliba and Y. Zhou, The Bloom of Perovskite Optoelectronics: Fundamental Science Matters, ACS Energy Lett., 2019, 4, 861-865.

5 W.-J. Yin, T. Shi and Y. Yan, Unique Properties of Halide Perovskites as Possible Origins of the Superior Solar Cell Performance, Adv. Mater., 2014, 26, 4653-4658.

6 Z. Li, T. R. Klein, D. H. Kim, M. Yang, J. J. Berry, M. F. A. M. van Hest and K. Zhu, Scalable fabrication of perovskite solar cells, Nat. Rev. Mater., 2018, 3, 18017.

7 S. Albrecht and B. Rech, Perovskite solar cells: On top of commercial photovoltaics, Nat. Energy, 2017, 2, 16196.

8 L. Meng, J. You and Y. Yang, Addressing the stability issue of perovskite solar cells for commercial applications, Nat. Commun., 2018, 9, 5265.

9 M. Lira-Cantú, Perovskite solar cells: Stability lies at interfaces, Nat. Energy, 2017, 2, 1-3.

10 R. Wang, M. Mujahid, Y. Duan, Z. K. Wang, J. Xue and Y. Yang, A Review of Perovskites Solar Cell Stability, Adv. Funct. Mater., 2019, 1808843, 1-25.

11 A. Abate and Perovskite Solar, Cells Go Lead Free, Joule, 2017, 1, 659-664.

12 Q. Jiang, Y. Zhao, X. Zhang, X. Yang, Y. Chen, Z. Chu, Q. Ye, X. Li, Z. Yin and J. You, Surface passivation of perovskite film for efficient solar cells, Nat. Photonics, 2019, 1-25.

13 O. US EPA, Lead Laws and Regulations.
14 F. Giustino and H. J. Snaith, Toward Lead-Free Perovskite Solar Cells, ACS Energy Lett., 2016, 1(6), 1233-1240.

15 N. K. Noel, S. D. Stranks, A. Abate, C. Wehrenfennig, S. Guarnera, A. A. Haghighirad, A. Sadhanala, G. E. Eperon, S. K. Pathak, M. B. Johnston, A. Petrozza, L. M. Herz and H. J. Snaith, Lead-free organic-inorganic tin halide perovskites for photovoltaic applications, Energy Environ. Sci., 2014, 7, 3061-3068.

16 F. Hao, C. C. Stoumpos, D. H. Cao, R. P. H. Chang and M. G. Kanatzidis, Lead-free solid-state organic-inorganic halide perovskite solar cells, Nat. Photonics, 2014, 8, 489-494.

17 W. Li, Z. Wang, F. Deschler, S. Gao, R. H. Friend and A. K. Cheetham, Chemically diverse and multifunctional hybrid organic-inorganic perovskites, Nat. Rev. Mater., 2017, 2, 16099.

18 L. Mao, C. C. Stoumpos and M. G. Kanatzidis, TwoDimensional Hybrid Halide Perovskites: Principles and Promises, J. Am. Chem. Soc., 2019, 141, 1171-1190.

19 D. B. Mitzi, Synthesis, Crystal Structure, and Optical and Thermal Properties of $\left(\mathrm{C}_{4} \mathrm{H}_{9} \mathrm{NH}_{3}\right)_{2} \mathrm{MI} 4(\mathrm{M}=\mathrm{Ge}, \mathrm{Sn}, \mathrm{Pb})$, Chem. Mater., 1996, 8(3), 791-800.

20 A. Babayigit, D. Duy Thanh, A. Ethirajan, J. Manca, M. Muller, H.-G. Boyen and B. Conings, Assessing the toxicity of $\mathrm{Pb}$ - and $\mathrm{Sn}$-based perovskite solar cells in model organism Danio rerio, Sci. Rep., 2016, 61(6), 1-11.

21 J. Li, H.-L. Cao, W.-B. Jiao, Q. Wang, M. Wei, I. Cantone, J. Lü and A. Abate, Biological impact of lead from halide perovskites reveals the risk of introducing a safe threshold, Nat. Commun., 2020, 11, 1-5.

22 T. Wu, X. Liu, X. Luo, X. Lin, D. Cui, Y. Wang, H. Segawa, Y. Zhang and L. Han, Lead-free tin perovskite solar cells, Joule, 2021, 5, 863-886.

23 I. Poli, G. W. Kim, E. L. Wong, A. Treglia, G. Folpini and A. Petrozza, High External Photoluminescence Quantum Yield in Tin Halide Perovskite Thin Films, ACS Energy Lett., 2021, 6, 609-611.

24 M. Lyu, J.-H. Yun, P. Chen, M. Hao and L. Wang, Addressing Toxicity of Lead: Progress and Applications of LowToxic Metal Halide Perovskites and Their Derivatives, $A d v$. Energy Mater., 2017, 7, 1602512.

25 S. Shao, W. Talsma, M. Pitaro, J. Dong, S. Kahmann, A. J. Rommens, G. Portale and M. A. Loi, Field-Effect Transistors Based on Formamidinium Tin Triiodide Perovskite, Adv. Funct. Mater., 2021, 31, 2008478.

26 A. Filippetti, S. Kahmann, C. Caddeo, A. Mattoni, M. Saba, A. Bosin and M. A. Loi, Fundamentals of tin iodide perovskites: a promising route to highly efficient, leadfree solar cells, J. Mater. Chem. A, 2021, 9, 11812-11826.

27 D. E. Scaife, P. F. Weller and W. G. Fisher, Crystal preparation and properties of cesium tin(II) trihalides, J. Solid State Chem., 1974, 9, 308-314.

28 D. E. Parry, M. J. Tricker and J. D. Donaldson, The electronic structure of $\mathrm{CsSnBr} 3$ and related trihalides; Studies using XPS and band theory, J. Solid State Chem., 1979, 28, 401-408. 
29 S. J. Clark, C. D. Flint and J. D. Donaldson, Luminescence and electrical conductivity of $\mathrm{CsSnBr} 3$, and related phases, J. Phys. Chem. Solids, 1981, 42, 133-135.

30 K. Yamada, S. Nose, T. Umehara, T. Okuda and S. Ichiba, 81Br NQR and 119Sn Mössbauer Study for $\operatorname{MSnBr}_{3}(\mathrm{M}=\mathrm{Cs}$ and $\mathrm{CH}_{3} \mathrm{NH}_{3}$ ), Bull. Chem. Soc. Jpn., 1988, 61, 4265-4268.

31 K. Yamada, T. Matsui, T. Tsuritani, T. Okuda and S. Ichiba, ${ }^{127} \mathrm{I}-\mathrm{NQR},{ }^{119} \mathrm{Sn}$ Mössbauer Effect, and Electrical Conductivity of $\mathrm{MSnI}_{3}\left(\mathrm{M}=\mathrm{K}, \mathrm{NH}_{4}, \mathrm{Rb}, \mathrm{Cs}\right.$, and $\left.\mathrm{CH}_{3} \mathrm{NH}_{3}\right)$, Z. Naturforsch., A: Phys. Sci., 1990, 45, 307-312.

32 K. Yamada, Y. Kuranaga, K. Ueda, S. Goto, T. Okuda and Y. Furukawa, Phase Transition and Electric Conductivity of $\mathrm{ASnCl}_{3}\left(\mathrm{~A}=\mathrm{Cs}\right.$ and $\left.\mathrm{CH}_{3} \mathrm{NH}_{3}\right)$, Bull. Chem. Soc. Jpn., 1998, 71, 127-134.

33 D. B. Mitzi, Templating and structural engineering in organic-inorganic perovskites, J. Chem. Soc., Dalton Trans., 2001, 0, 1-12.

34 D. B. Mitzi, C. A. Feild, Z. Schlesinger and R. B. Laibowitz, Transport, Optical, and Magnetic Properties of the Conducting Halide Perovskite $\mathrm{CH}_{3} \mathrm{NH}_{3} \mathrm{SnI}_{3}, \mathrm{~J}$. Solid State Chem., 1995, 114, 159-163.

35 D. B. Mitzi, C. A. Feild, W. T. A. Harrison and A. M. Guloy, Conducting tin halides with a layered organic-based perovskite structure, Nature, 1994, 369, 467-469.

36 D. B. Mitzi, S. Wang, C. A. Feild, C. A. Chess and A. M. Guloy, Conducting Layered Organic-inorganic Halides Containing-Oriented Perovskite Sheets, Science, 1995, 267, 1473-1476.

37 A. Dodabalapur, L. Torsi, H. E. Katz, A. Callegari and J. M. Shaw, Organic Transistors: Two-Dimensional Transport and Improved Electrical Characteristics, Science, 1995, 268, 270-271.

38 D. B. Mitzi, C. D. Dimitrakopoulos and L. L. Kosbar, Structurally Tailored Organic-Inorganic Perovskites: Optical Properties and Solution-Processed Channel Materials for Thin-Film Transistors, Chem. Mater., 2001, 13(10), 3728-3740.

39 I. Chung, B. Lee, J. He, R. P. H. Chang and M. G. Kanatzidis, All-solid-state dye-sensitized solar cells with high efficiency, Nature, 2012, 485, 486-489.

40 Z. Chen, J. J. Wang, Y. Ren, C. Yu and K. Shum, Schottky solar cells based on $\mathrm{CsSnI}_{3}$ thin-films, Appl. Phys. Lett., 2012, 101, 093901.

41 G. Murtaza, S. Muhammad, S. Naeem, M. Khalid and A. Manzar, Physical Properties of $\mathrm{CsSnM}_{3}(\mathrm{M}=\mathrm{Cl}, \mathrm{Br}, \mathrm{I})$ : A First Principle Study, Acta Phys. Pol., A, 2013, 71(15), 102-107.

42 L. Huang and W. R. L. Lambrecht, Electronic band structure, phonons, and exciton binding energies of halide perovskites $\mathrm{CsSnCl}_{3}, \mathrm{CsSnBr}_{3}$, and $\mathrm{CsSnI}_{3}$, Phys. Rev. B: Condens. Matter Mater. Phys., 2013, 88, 165203.

43 C. C. Stoumpos, C. D. Malliakas and M. G. Kanatzidis, Semiconducting Tin and Lead Iodide Perovskites with Organic Cations: Phase Transitions, High Mobilities, and Near-Infrared Photoluminescent Properties, Inorg. Chem., 2015, 52(15), 9019-9038.
44 F. Brivio, A. B. Walker and A. Walsh, Structural and electronic properties of hybrid perovskites for highefficiency thin-film photovoltaics from first-principles, APL Mater., 2013, 1, 042111.

45 J.-H. Im, I.-H. Jang, N. Pellet, M. Grätzel and N.-G. Park, Growth of $\mathrm{CH}_{3} \mathrm{NH}_{3} \mathrm{PbI}_{3}$ cuboids with controlled size for high-efficiency perovskite solar cells, Nat. Nanotechnol., 2014, 9, 927-932.

46 Z. Ren, A. Ng, Q. Shen, H. C. Gokkaya, J. Wang, L. Yang, W.K. Yiu, G. Bai, A. B. Djurišić, W. W. Leung, J. Hao, W. K. Chan and C. Surya, Thermal Assisted Oxygen Annealing for High Efficiency Planar $\mathrm{CH}_{3} \mathrm{NH}_{3} \mathrm{PbI}_{3}$ Perovskite Solar Cells, Sci. Rep., 2015, 4, 6752.

47 M. A. Green, A. Ho-Baillie and H. J. Snaith, The emergence of perovskite solar cells, Nat. Photonics, 2014, 8, 506-514.

48 S. J. Lee, S. S. Shin, Y. C. Kim, D. Kim, T. K. Ahn, J. H. Noh, J. Seo and S. Il Seok, Fabrication of Efficient Formamidinium Tin Iodide Perovskite Solar Cells through $\mathrm{SnF}_{2}-$ Pyrazine Complex, J. Am. Chem. Soc., 2016, 138, 3974-3977.

49 J. Pascual, M. Flatken, R. Felix, G. Li, S.-H. Turren-Curz, M. H. Aldamasy, C. Hartmann, M. Li, D. Di Girolamo, G. Nasti, E. Hüsam, R. G. Wilks, A. Dallmann, M. Bär, A. Hoell and A. Abate, Fluoride Chemistry in Tin Halide Perovskites, Angew. Chem., 2021, 60, 2-11.

50 W. Liao, D. Zhao, Y. Yu, C. R. Grice, C. Wang, A. J. Cimaroli, P. Schulz, W. Meng, K. Zhu, R.-G. Xiong and Y. Yan, Lead-Free Inverted Planar Formamidinium Tin Triiodide Perovskite Solar Cells Achieving Power Conversion Efficiencies up to 6.22\%, Adv. Mater., 2016, 28, 9333-9340.

51 Z. Zhao, F. Gu, Y. Li, W. Sun, S. Ye, H. Rao, Z. Liu, Z. Bian and C. Huang, Mixed-Organic-Cation Tin Iodide for LeadFree Perovskite Solar Cells with an Efficiency of 8.12\%, Adv. Sci., 2017, 4, 1700204.

52 Y. Liao, H. Liu, W. Zhou, D. Yang, Y. Shang, Z. Shi, B. Li, X. Jiang, L. Zhang, L. N. Quan, R. Quintero-Bermudez, B. R. Sutherland, Q. Mi, E. H. Sargent and Z. Ning, Highly Oriented Low-Dimensional Tin Halide Perovskites with Enhanced Stability and Photovoltaic Performance, J. Am. Chem. Soc., 2017, 139, 6693-6699.

53 W. Ke, C. C. Stoumpos, M. Zhu, L. Mao, I. Spanopoulos, J. Liu, O. Y. Kontsevoi, M. Chen, D. Sarma, Y. Zhang, M. R. Wasielewski and M. G. Kanatzidis, Enhanced photovoltaic performance and stability with a new type of hollow 3D perovskite $\{$ en $\} \mathrm{FASnI}_{3}, S c i$. Adv., 2017, 3, e1701293.

54 W. Ke, C. C. Stoumpos, I. Spanopoulos, L. Mao, M. Chen, M. R. Wasielewski and M. G. Kanatzidis, Efficient LeadFree Solar Cells Based on Hollow \{en\} $\mathrm{MASnI}_{3}$ Perovskites, J. Am. Chem. Soc., 2017, 139, 14800-14806.

55 S. Shao, J. Liu, G. Portale, H.-H. Fang, G. R. Blake, G. H. ten Brink, L. J. A. Koster and M. A. Loi, Highly Reproducible Sn-Based Hybrid Perovskite Solar Cells with 9\% Efficiency, Adv. Energy Mater., 2018, 8, 1702019.

56 C. Ran, J. Xi, W. Gao, F. Yuan, T. Lei, B. Jiao, X. Hou and Z. Wu, Bilateral Interface Engineering toward Efficient 2D-3D Bulk Heterojunction Tin Halide Lead-Free Perovskite Solar Cells, ACS Energy Lett., 2018, 3(3), 713-721. 
57 J. Liu, M. Ozaki, S. Yakumaru, T. Handa, R. Nishikubo, Y. Kanemitsu, A. Saeki, Y. Murata, R. Murdey and A. Wakamiya, Lead-Free Solar Cells based on Tin Halide Perovskite Films with High Coverage and Improved Aggregation, Angew. Chem., Int. Ed., 2018, 57, 13221-13225.

58 E. Jokar, C.-H. Chien, A. Fathi, M. Rameez, Y.-H. Chang and E. W.-G. Diau, Slow surface passivation and crystal relaxation with additives to improve device performance and durability for tin-based perovskite solar cells, Energy Environ. Sci., 2018, 11, 2353-2362.

59 E. Jokar, C.-H. Chien, C.-M. Tsai, A. Fathi and E. W.G. Diau, Robust Tin-Based Perovskite Solar Cells with Hybrid Organic Cations to Attain Efficiency Approaching 10\%, Adv. Mater., 2019, 31, 1804835.

60 F. Wang, X. Jiang, H. Chen, Y. Shang, H. Liu, J. Wei, W. Zhou, H. He, W. Liu and Z. Ning, 2D-Quasi-2D-3D Hierarchy Structure for Tin Perovskite Solar Cells with Enhanced Efficiency and Stability, Joule, 2018, 2, 2732-2743.

61 K. Nishimura, M. A. Kamarudin, D. Hirotani, K. Hamada, Q. Shen, S. Iikubo, T. Minemoto, K. Yoshino and S. Hayase, Lead-free tin-halide perovskite solar cells with 13\% efficiency, Nano Energy, 2020, 74, 104858.

62 C. Wang, Y. Zhang, F. Gu, Z. Zhao, H. Li, H. Jiang, Z. Bian and Z. Liu, Illumination Durability and High-Efficiency Sn-Based Perovskite Solar Cell under Coordinated Control of Phenylhydrazine and Halogen Ions, Matter, 2021, 4, 709-721.

63 X. Jiang, H. Li, Q. Zhou, Q. Wei, M. Wei, L. Jiang, Z. Wang, Z. Peng, F. Wang, Z. Zang, K. Xu, Y. Hou, S. Teale, W. Zhou, R. Si, X. Gao, E. H. Sargent and Z. Ning, One-Step Synthesis of $\mathrm{SnI}_{2} \cdot(\mathrm{DMSO})_{x}$ Adducts for High-Performance Tin Perovskite Solar Cells, J. Am. Chem. Soc., 2021, 143, 10970-10976.

64 X. Liu, T. Wu, J. Y. Chen, X. Meng, X. He, T. Noda, H. Chen, X. Yang, H. Segawa, Y. Wang and L. Han, Templated growth of $\mathrm{FASnI}_{3}$ crystals for efficient tin perovskite solar cells, Energy Environ. Sci., 2020, 13, 2896-2902.

65 G. Nasti and A. Abate, Adv. Energy Mater., 2020, 10, 1902467.

66 D. He, L. Shen, Y. Bai and L. Wang, Rational strategies toward efficient and stable lead-free tin halide perovskite solar cells, Mater. Chem. Front., 2021, 5, 4107-4127.

67 T. Leijtens, R. Prasanna, A. Gold-Parker, M. F. Toney and M. D. McGehee, Mechanism of Tin Oxidation and Stabilization by Lead Substitution in Tin Halide Perovskites, ACS Energy Lett., 2017, 2, 2159-2165.

68 D. Ricciarelli, D. Meggiolaro, F. Ambrosio and F. De Angelis, Instability of tin iodide perovskites: bulk pdoping versus surface tin oxidation, ACS Energy Lett., 2020, 5, 2787-2795.

69 M. Ozaki, Y. Katsuki, J. Liu, T. Handa, R. Nishikubo, S. Yakumaru, Y. Hashikawa, Y. Murata, T. Saito, Y. Shimakawa, Y. Kanemitsu, A. Saeki and A. Wakamiya, Solvent-coordinated tin halide complexes as purified precursors for tin-based perovskites, ACS Omega, 2017, 2, 7016-7021.
70 Y. Kanemitsu, A. Wakamiya, T. Nakamura, T. Handa and R. Murdey, Materials chemistry approach for efficient lead-free tin halide perovskite solar cells, ACS Appl. Electron. Mater., 2020, 2, 3794-3804.

71 N. K. Tailor, M. Abdi-Jalebi, V. Gupta, H. Hu, M. I. Dar, G. Li and S. Satapathi, J. Mater. Chem. A, 2020, 8, 21356-21386.

72 F. Huang, M. Li, P. Siffalovic, G. Cao and J. Tian, Energy Environ. Sci., 2019, 12, 518-549.

73 M. Jung, S. G. Ji, G. Kim and S. Il Seok, Chem. Soc. Rev., 2019, 48, 2011-2038.

74 M. I. Saidaminov, I. Spanopoulos, J. Abed, W. Ke, J. Wicks, M. G. Kanatzidis and E. H. Sargent, ACS Energy Lett., 2020, 5, 1153-1155.

75 J. Pascual, G. Nasti, M. H. Aldamasy, J. A. Smith, M. Flatken, N. Phung, D. Di Girolamo, S.-H. Turren-Cruz, M. Li, A. Dallmann, R. Avolio and A. Abate, Origin of Sn(II) oxidation in tin halide perovskites, Mater. Adv., 2020, 1, 1066-1070.

76 A. Monga, S. Bagchi and A. Sharma, New J. Chem., 2018, 42, 1551-1576.

77 K. Mislow, T. Simmons, J. T. Melillo and A. L. Ternay, The Hydrogen Chloride-Catalyzed Racemization of Sulfoxides, J. Am. Chem. Soc., 1964, 86, 1452-1453.

78 D. Di Girolamo, J. Pascual, M. H. Aldamasy, Z. Iqbal, G. Li, E. Radicchi, M. Li, S. H. Turren-Cruz, G. Nasti, A. Dallmann, F. De Angelis and A. Abate, Solvents for Processing Stable Tin Halide Perovskites, ACS Energy Lett., 2021, 959-968.

79 G. Grancini, S. Marras, M. Prato, C. Giannini, C. Quarti, F. De Angelis, M. De Bastiani, G. E. Eperon, H. J. Snaith, L. Manna and A. Petrozza, The impact of the crystallization processes on the structural and optical properties of hybrid perovskite films for photovoltaics, J. Phys. Chem. Lett., 2014, 5, 3836-3842.

80 Y. Yang, H. Lu, S. Feng, L. Yang, H. Dong, J. Wang, C. Tian, L. Li, H. Lu, J. Jeong, S. M. Zakeeruddin, Y. Liu, M. Grätzel and A. Hagfeldt, Modulation of perovskite crystallization processes towards highly efficient and stable perovskite solar cells with MXene quantum dot-modified $\mathrm{SnO}_{2}$, Energy Environ. Sci., 2021, 14, 3447-3454.

81 Y. Xu, M. Wang, Y. Lei, Z. Ci and Z. Jin, Adv. Energy Mater., 2020, 10, 2002558.

82 N. Alhazmi, E. Pineda, J. Rawle, J. R. Howse and A. D. F. Dunbar, Perovskite Crystallization Dynamics during Spin-Casting: An in Situ Wide-Angle X-ray Scattering Study, ACS Appl. Energy Mater., 2020, 3, 6155-6164.

83 L. Kuai, J. Li, Y. Li, Y. Wang, P. Li, Y. Qin, T. Song, Y. Yang, Z. Chen, X. Gao and B. Sun, Revealing Crystallization Dynamics and the Compositional Control Mechanism of 2D Perovskite Film Growth by in Situ Synchrotron-Based GIXRD, ACS Energy Lett., 2020, 5, 8-16.

84 J. Dong, S. Shao, S. Kahmann, A. J. Rommens, D. HermidaMerino, G. H. ten Brink, M. A. Loi and G. Portale, Mechanism of Crystal Formation in Ruddlesden-Popper Sn-Based Perovskites, Adv. Funct. Mater., 2020, 30, 2001294. 
85 A. Krishna, S. Gottis, M. K. Nazeeruddin and F. Sauvage, Mixed Dimensional 2D/3D Hybrid Perovskite Absorbers: The Future of Perovskite Solar Cells?, Adv. Funct. Mater., 2019, 29, 1-20.

86 D. H. Cao, C. C. Stoumpos, T. Yokoyama, J. L. Logsdon, T. Bin Song, O. K. Farha, M. R. Wasielewski, J. T. Hupp and M. G. Kanatzidis, Thin Films and Solar Cells Based on Semiconducting Two-Dimensional Ruddlesden-Popper $\left(\mathrm{CH}_{3}\left(\mathrm{CH}_{2}\right)_{3} \mathrm{NH}_{3}\right)_{2}\left(\mathrm{CH}_{3} \mathrm{NH}_{3}\right)_{n-1} \mathrm{SnnI}_{3 n+1}$ Perovskites, ACS Energy Lett., 2017, 2, 982-990.

87 L. Lanzetta, N. Aristidou and S. A. Haque, J. Phys. Chem. Lett., 2020, 11, 574-585.

88 M. Awais, R. L. Kirsch, V. Yeddu and M. I. Saidaminov, ACS Mater. Lett., 2021, 3, 299-307.

89 D. Meggiolaro, D. Ricciarelli, A. A. Alasmari, F. A. S. Alasmary and F. De Angelis, Tin versus Lead Redox Chemistry Modulates Charge Trapping and Self-Doping in Tin/Lead Iodide Perovskites, J. Phys. Chem. Lett., 2020, 11, 3546-3556.

90 R. S. Drago, J. Phys. Chem., 1958, 62, 353-357.

91 M. H. Kumar, S. Dharani, W. L. Leong, P. P. Boix, R. R. Prabhakar, T. Baikie, C. Shi, H. Ding, R. Ramesh, M. Asta, M. Graetzel, S. G. Mhaisalkar and N. Mathews, Lead-free halide perovskite solar cells with high photocurrents realized through vacancy modulation, Adv. Mater., 2014, 26, 7122-7127.

92 T. M. Koh, T. Krishnamoorthy, N. Yantara, C. Shi, W. L. Leong, P. P. Boix, A. C. Grimsdale, S. G. Mhaisalkar and N. Mathews, Formamidinium tin-based perovskite with low $\mathrm{Eg}$ for photovoltaic applications, J. Mater. Chem. A, 2015, 3, 14996-15000.

93 C. Hartmann, S. Gupta, T. Bendikov, X. Kozina, T. Kunze, R. Félix, G. Hodes, R. G. Wilks, D. Cahen and M. Bär, Impact of $\mathrm{SnF}_{2}$ Addition on the Chemical and Electronic Surface Structure of $\mathrm{CsSnBr}_{3}$, ACS Appl. Mater. Interfaces, 2020, 12, 12353-12361.

94 P. Zhu, C. Chen, S. Gu, R. Lin and J. Zhu, CsSnI 3 Solar Cells via an Evaporation-Assisted Solution Method, Sol. RRL, 2018, 2, 1700224.

95 X. Liu, Y. Wang, T. Wu, X. He, X. Meng, J. Barbaud, H. Chen, H. Segawa, X. Yang and L. Han, Efficient and stable tin perovskite solar cells enabled by amorphouspolycrystalline structure, Nat. Commun., 2020, 11, 1-7.

96 J. H. Heo, J. Kim, H. Kim, S. H. Moon, S. H. Im and K. H. Hong, Roles of $\mathrm{SnX}_{2}(\mathrm{X}=\mathrm{F}, \mathrm{Cl}, \mathrm{Br})$ Additives in TinBased Halide Perovskites toward Highly Efficient and Stable Lead-Free Perovskite Solar Cells, J. Phys. Chem. Lett., 2018, 9, 6024-6031.

97 T. Bin Song, T. Yokoyama, S. Aramaki and M. G. Kanatzidis, Performance enhancement of lead-free tinbased perovskite solar cells with reducing atmosphereassisted dispersible additive, ACS Energy Lett., 2017, 2, 897-903.

98 T. Wang and F. Yan, Chem. - Asian J., 2020, 15, 1524-1535. 99 C. Wang, F. Gu, Z. Zhao, H. Rao, Y. Qiu, Z. Cai, G. Zhan, X. Li, B. Sun, X. Yu, B. Zhao, Z. Liu, Z. Bian and C. Huang,
Self-Repairing Tin-Based Perovskite Solar Cells with a Breakthrough Efficiency Over 11\%, Adv. Mater., 2020, 32(31), 1907623.

100 X. He, T. Wu, X. Liu, Y. Wang, X. Meng, J. Wu, T. Noda, X. Yang, Y. Moritomo, H. Segawa and L. Han, Highly efficient tin perovskite solar cells achieved in a wide oxygen concentration range, J. Mater. Chem. A, 2020, 8, 2760-2768.

101 T. Wang, Q. Tai, X. Guo, J. Cao, C. K. Liu, N. Wang, D. Shen, Y. Zhu, C. S. Lee and F. Yan, Highly Air-Stable Tin-Based Perovskite Solar Cells through Grain-Surface Protection by Gallic Acid, ACS Energy Lett., 2020, 5, 1741-1749.

102 M. E. Kayesh, T. H. Chowdhury, K. Matsuishi, R. Kaneko, S. Kazaoui, J. J. Lee, T. Noda and A. Islam, Enhanced Photovoltaic Performance of FASnI $_{3}$-Based Perovskite Solar Cells with Hydrazinium Chloride Coadditive, ACS Energy Lett., 2018, 3, 1584-1589.

103 F. Gu, S. Ye, Z. Zhao, H. Rao, Z. Liu, Z. Bian and C. Huang, Improving Performance of Lead-Free Formamidinium Tin Triiodide Perovskite Solar Cells by Tin Source Purification (Solar RRL 10/2018), Sol. RRL, 2018, 2, 1870217.

104 T. Nakamura, S. Yakumaru, M. A. Truong, K. Kim, J. Liu, S. Hu, K. Otsuka, R. Hashimoto, R. Murdey, T. Sasamori, H. Do Kim, H. Ohkita, T. Handa, Y. Kanemitsu and A. Wakamiya, Sn(Iv)-free tin perovskite films realized by in situ $\operatorname{Sn}(0)$ nanoparticle treatment of the precursor solution, Nat. Commun., 2020, 11, 1-8.

105 N. Sun, W. Gao, H. Dong, Y. Liu, X. Liu, Z. Wu, L. Song, C. Ran and Y. Chen, Architecture of p-i-n Sn-Based Perovskite Solar Cells: Characteristics, Advances, and Perspectives, ACS Energy Lett., 2021, 6, 2863-2875.

106 S. Tao, I. Schmidt, G. Brocks, J. Jiang, I. Tranca, K. Meerholz and S. Olthof, Absolute energy level positions in tin- and lead-based halide perovskites, Nat. Commun., 2019, 10, 1-10.

107 N. Wang, Y. Zhou, M. G. Ju, H. F. Garces, T. Ding, S. Pang, X. C. Zeng, N. P. Padture and X. W. Sun, HeterojunctionDepleted Lead-Free Perovskite Solar Cells with CoarseGrained B- $\gamma-\mathrm{CsSnI}_{3}$ Thin Films, Adv. Energy Mater., 2016, 6, 1601130.

108 K. Hamada, R. Tanaka, M. A. Kamarudin, Q. Shen, S. Iikubo, T. Minemoto, K. Yoshino, T. Toyoda, T. Ma, D. W. Kang and S. Hayase, Enhanced Device Performance with Passivation of the TiO2 Surface Using a Carboxylic Acid Fullerene Monolayer for a SnPb Perovskite Solar Cell with a Normal Planar Structure, ACS Appl. Mater. Interfaces, 2020, 12, 17776-17782.

109 T. Yokoyama, Y. Nishitani, Y. Miyamoto, S. Kusumoto, R. Uchida, T. Matsui, K. Kawano, T. Sekiguchi and Y. Kaneko, Improving the Open-Circuit Voltage of SnBased Perovskite Solar Cells by Band Alignment at the Electron Transport Layer/Perovskite Layer Interface, ACS Appl. Mater. Interfaces, 2020, 12, 27131-27139.

110 W. Ke, P. Priyanka, S. Vegiraju, C. C. Stoumpos, I. Spanopoulos, C. M. M. Soe, T. J. Marks, M. C. Chen 
and M. G. Kanatzidis, Dopant-Free Tetrakis-Triphenylamine Hole Transporting Material for Efficient Tin-Based Perovskite Solar Cells, J. Am. Chem. Soc., 2018, 140, 388-393.

111 J. Cao, Q. Tai, P. You, G. Tang, T. Wang, N. Wang and F. Yan, Enhanced performance of tin-based perovskite solar cells induced by an ammonium hypophosphite additive, J. Mater. Chem. A, 2019, 7, 26580-26585.

112 C. Liu, J. Tu, X. Hu, Z. Huang, X. Meng, J. Yang, X. Duan, L. Tan, Z. Li and Y. Chen, Enhanced Hole Transportation for Inverted Tin-Based Perovskite Solar Cells with High Performance and Stability, Adv. Funct. Mater., 2019, 29, 1808059.
113 S. Emami, J. Martins, D. Ivanou and A. Mendes, Advanced hermetic encapsulation of perovskite solar cells: the route to commercialization, J. Mater. Chem. A, 2020, 8, 2654-2662.

114 J. Li, R. Xia, W. Qi, X. Zhou, J. Cheng, Y. Chen, G. Hou, Y. Ding, Y. Li, Y. Zhao and X. Zhang, Encapsulation of perovskite solar cells for enhanced stability: Structures, materials and characterization, J. Power Sources, 2021, 485, 229313.

115 F. Alta and E. S. Asu, Best Research-Cell Efficiencies, 2020, p. 2020 . 